\title{
1 Monoclonal antibodies targeting the influenza virus N6 neuraminidase
}

3 Shirin Strohmeier, ${ }^{a, b}$, Fatima Amanat, ${ }^{a, c}$ Juan Manuel Carreño, ${ }^{a}$ Florian Krammer ${ }^{a} \#$

5 aDepartment of Microbiology, Icahn School of Medicine at Mount Sinai, New York, NY,

6 USA

7 bepartment of Biotechnology, University of Natural Resources and Life Sciences,

8 Vienna, Austria

$9{ }^{\mathrm{C}}$ Graduate School of Biomedical Sciences, Icahn School of Medicine at Mount Sinai,

10 New York, New York, USA

11 Running Head: Monoclonal antibodies targeting the influenza virus N6 neuraminidase

12 \#Address correspondence to Florian Krammer, florian.krammer@mssm.edu

13 Abstract, Importance:

14 Main text: 


\section{Abstract}

25 Influenza A viruses are a diverse species that include 16 hemagglutinin (HA) subtypes 26 and 9 neuraminidase (NA) subtypes. While the antigenicity of many HA subtypes is 27 reasonably well studied, less is known about NA antigenicity, especially when it comes

28 to non-human subtypes that only circulate in animal reservoirs. The N6 NA subtypes are 29 mostly found in viruses infecting birds. However, they have also been identified in 30 viruses that infect mammals, such as swine and seals. More recently, highly pathogenic 31 H5N6 subtype viruses have caused rare infections and mortality in humans. Here, we 32 generated murine mAbs to the N6 NA, characterized their breadth and antiviral 33 properties in vitro and in vivo and mapped their epitopes by generating escape mutant 34 viruses. We found that the antibodies had broad reactivity across the American and 35 Eurasian N6 lineages, but relatively little binding and inhibition of the H5N6 NA. Several 36 of the antibodies exhibited strong NA inhibition activity and some also showed activity in 37 the antibody dependent cellular cytotoxicity reporter assay and neutralization assay. In 38 addition, we generated escape mutant viruses for six monoclonal antibodies and found 39 mutations on the lateral ridge of the NA. Lastly, we observed variable protection in 40 H4N6 and H5N6 mouse challenge models when the antibodies were given 41 prophylactically.

44 The N6 NA has recently gained prominence due to the emergence of highly pathogenic 45 H5N6 viruses. Currently, there is limited characterization of the antigenicity of avian N6 46 neuraminidase. Our data is an important first step towards a better understanding of the 47 N6 NA antigenicity.

\section{Introduction}


50 Influenza A viruses are categorized based on 16 hemagglutinin (HAs) subtypes and 9 51 neuraminidase (NAs) subtypes which are all found in the avian reservoirs (1). Two HA-

52 like and NA-like virus isolates have also been found in bats $(2,3)$. HAs facilitate binding

53 and entry into host cells and immune responses to HA have been correlated with

54 protection from infection and/or disease. As such, the antigenicity of numerous HAs is

55 highly characterized. Despite increased efforts to better understand NA antigenicity of

56 human seasonal N1, N2 and type B NAs (4-14) for the design of improved influenza

57 virus vaccines, little work has been done on non-human NA subtypes (group 1: N1, N4,

58 N5, N8; group 2: N2, N3, N6, N7, N9), and most work has focused almost exclusively

59 on the N9 NA (15-20).

60 Viruses composed of the N6 NA circulate in avian species in combination with all 16 HA

61 subtypes, although H3N6 (21), H4N6 (22), H5N6 (22), H6N6 (23) and H13N6 (24) are

62 most common. In addition, H3N6, H4N6, H5N6 and H6N6 have been isolated from

63 swine (25-28), H4N6 viruses have been found in marine mammals (29) and H5N6

64 viruses have been found in cats (22). Avian H7N6 viruses have also been shown to be

65 transmissible in guinea pigs (30). The N6 subtype can be further divided into two

66 lineages, a predominantly Eurasian lineage (EAL) and a predominantly North American

67 lineage (NAL) (Figure 1) (1), although isolates from North America sometimes fall into

68 the Eurasian lineage and vice versa. Some N6 isolates have also been found to be

69 resistant to NA inhibitors, which is a concern $(31,32)$. Another peculiarity that seems to

70 be specific for N6 NAs is the ability of some strains to aid cleavage of HA in concert with

71 thrombin-like proteases, as observed for an H7N6 virus isolate (33), which allows

72 systemic replication of these viruses without the presence of a polybasic cleavage site

73 of the HA.

74 With the emergence of H5NX viruses in the early 2000s (34), highly pathogenic H5N6

75 viruses hosting a Eurasian N6 appeared in chickens in 2013 and have since 2015 also

76 infected humans and have - according to the World Health Organization (WHO) as of

77 December $18^{\text {th }} 2020$ (35) - led to 8 fatalities (36-40). Therefore, H5N6 vaccine

78 candidates are being prepared (e.g. (H5N6)-PR8-IDCDC-RG42A). While these 
79 vaccines are focused on inducing anti-HA antibodies, it would also be important to

80 better understand the antigenicity of the N6 NA. Here, using murine hybridoma

81 technology, we generated and characterized monoclonal antibodies (mAbs) to better

82 understand breadth, functionality, epitopes and protective effect of the antibody

83 response to N6 NA.

\section{Results}

\section{Generation of mAbs}

88 To generate and isolate mAbs, we vaccinated mice first with

89 A/swine/Missouri/A01727926/2015 (H4N6, NAL) twice in a three-week interval (41).

90 Three weeks later mice were immunized with A/Shenzhen/1/2016 (H5N6, EAL). After

91 another three weeks, one animal was boosted with A/duck/Zhejiang/D9/2013 (H4N6,

92 EAL), three days later the animal was euthanized, the spleen was removed and a

93 hybridoma fusion performed. Ten mAbs with strong reactivity to a recombinant version

94 of the N6 of A/swine/Missouri/A01727926/2015 were identified as a result of the

95 hybridoma fusion (Table 1).

96

\section{Characterization of antibody binding breadth}

98 First, we wanted to characterize the binding breadth of the ten mAbs. To do this, we

99 recombinantly expressed the N6 of A/swine/Missouri/A01727926/2015 (H4N6, NAL),

100 A/Shenzhen/1/2016 (H5N6, EAL), A/Caspian seal/Russia/T1/2012 (H4N6, EAL) and

$101 \mathrm{~A} /$ duck/Zhejiang/D9/2013 (H4N6, EAL) as soluble tetramers. These proteins were used

102 as substrates for enzyme-linked immunosorbent assays (ELISAs). The N9 protein of

103 A/Anhui/1/2013 (H7N9) was used as a negative control to ensure that mAbs were 104 specific to the N6. All mAbs, except KL-N6-3F10, displayed strong reactivity to the N6 
105 NA of A/swine/Missouri/A01727926/2015 (NAL, Figure 2A). MAb KL-N6-3F10 while still

106 binding, had a lower endpoint titer compared to the other nine mAbs. Binding to the N6

107 NA of A/duck/Zhejiang/D9/2013 (EAL) and A/Caspian seal/Russia/T1/2012 (EAL) was

108 more variable, but all mAbs reacted well in an ELISA assay and better than the positive

109 control (Figure 2B and C). Interestingly, binding to the recombinant N6 NA of

110 A/Shenzhen/1/2016 (EAL) was low for most mAbs, and only mAb KL-N6-3F10 showed

111 decent binding. Lower binding activity was observed for KL-N6-3B5, KL-N6-3C5 and

112 KL-N6-3E1 (Figure 2D). None of the mAbs bound to recombinant N9 NA which shows

113 that antibodies were specific to the N6 (Figure 2E). In addition to the ELISA, we also

114 performed an immunofluorescence assay (IF) of Madin Darby canine kidney (MDCK)

115 cells infected with wild type isolates and re-assortant viruses from both lineages. In this

116 assay, a majority of mAbs bound to all six tested EAL viruses (Figure 3). Interestingly,

117 more antibodies showed binding to A/Shenzhen/1/2016 including KL-N6-2E8, KL-N6-

118 3B5, KL-N6-3C5, KL-N6-3C7, KL-N6-3D5 KL-N6-3E1 and KL-N6-3F10 in the IF assay.

119 Similar to the EAL lineage, all mAbs bound to cells infected by all eight NAL viruses in

120 this assay (Figure 4).

\section{In vitro functional characterization of mAbs}

123 Next, we wanted to test the in vitro functionality of the isolated mAbs in NA inhibition

$124(\mathrm{NI})$, plaque reduction neutralization and antibody-dependent cellular cytotoxicity 125 (ADCC) reporter assays. NI was measured against A/duck/Czechoslovakia/1956 (EAL, 126 H4N6), A/swine/Missouri/A01727926/2015 (NAL, H4N6) and two versions of 127 A/Shenzhen/1/2016 (EAL, H5N6). MAbs KL-N6-2E8, KL-N6-3C7 and KL-N6-3D5 128 showed the strongest inhibition of A/duck/Czechoslovakia/1956 followed by KL-N6-1G9, 129 KL-N6-1A5, KL-N6-3F10, KL-N6-1D4, KL-N6-3E1, KL-N6-3B5 and finally KL-N6-3C6

130 (Figure 5A). The order was similar for A/swine/Missouri/A01727926/2015 except that 131 KL-N6-3F10 was only slightly better than KL-N6-3B5 and finally KL-N6-3C6 (Figure 132 5B). NI activity was very weak for most mAbs against A/Shenzhen/1/2016, and only KL- 
133 N6-3F10 showed reasonable activity, albeit even that was low (Figure 5C). Of note, HA 134 stalk-reactive antibody CR9114 $(42,43)$, which can inhibit NA through steric hindrance 135 (44), was used as positive control. CR9114 performed relatively well against 136 A/Shenzhen/1/2016. The N6 NA of A/Shenzhen/1/2016 has a stalk deletion, which is 137 known to confer pathogenicity to highly pathogenic avian influenza (HPAl) viruses and 138 we reasoned that a longer stalk may make the NA more vulnerable to NI. We, therefore, 139 created a loss of function version of A/Shenzhen/1/2016 which featured a regular stalk 140 length. While no improvement was seen for the other mAbs, KL-N6-3F10 performed 141 much better against the 'long stalk' version of A/Shenzhen/1/2016 (Figure 5D). CR9114 142 performed less well, which makes sense since a longer stalk of the NA probably 143 overcomes some of the steric hindrance exerted by anti-stalk mAbs.

144 Using A/duck/Czechoslovakia/1956 (H4N6), we also performed plaque reduction 145 neutralization assays (PRNAs) to measure both reduction of plaque size (a common 146 feature of anti-NA mAbs) and reduction of plaque numbers (usually referred to as 147 neutralization). All mAbs reduced plaque size to various degrees, mostly in accordance 148 with their $\mathrm{NI}$ activity (Figure 6A). Plaque number was only reduced effectively by mAbs 149 KL-N6-1A5, KL-N6-1D4, KL-N6-1G9, KL-N6-3B5, KL-N6-3D5 and KL-N6-3E1 (Figure 150 6B). Interestingly, these results are not in concordance with the $\mathrm{NI}$ activity suggesting 151 that neutralization requires a different mechanism other than $\mathrm{NI}$ activity for these mAbs.

152 ADCC reporter activity was also measured since it has been shown to be important for 153 the protective effect of some NA mAbs. All antibodies except KL-N6-3F10 exhibited 154 reasonable but variable ADCC reporter activity against

155 A/swine/Missouri/A01727926/2015. Especially KL-N6-3B5 and KL-N6-3C6 showed 156 outstanding activity that was higher than that of the positive control, stalk mAbs CR9114 157 which is known for its ADCC activity (Figure 6C). Interestingly, the ADCC activity of the $158 \mathrm{mAbs}$ was much lower against cells infected with A/duck/Czechoslovakia/1956 (Figure 159 6D) or A/Shenzhen/1/2016 (Figure 6E), but also here KL-N6-3B5 and KL-N6-3C6 160 performed better than the other mAbs. 


\section{Epitope mapping via escape mutant generation}

163 To learn more about the epitopes of the generated mAbs, we generated escape mutant 164 viruses (EMVs) by subjecting A/duck/Czechoslovakia/1956 to increasing antibody 165 pressure by passaging the virus continually with increasing amounts of antibody. An 166 irrelevant mAb directed against the Lassa virus glycoprotein was included as control 167 (45). We succeeded in generating six different EMVs. The EMV selected by KL-N6-1A5 168 showed a strong reduction in NI compared to wild type. This EMV carried a G221E 169 mutation on the lateral side of the NA (Figure 7). Similar phenotypes were seen for the 170 KL-N6-2E8 (N249S) and KL-N6-3E1 (G221E) EMVs. For the KL-N6-1D4 (R250G), KL171 N6-1G9 (R250K) and KL-N6-3D5 (P246Q) EMVs, a complete loss of NI was observed. 172 When the six mAbs were then cross-tested with the six EMVs, we found that the KL-N6173 1A5 EMV (G221E) also strongly reduced NI of KL-N6-1D4 and KL-N6-1G9 while KL174 N6-2E8 and KL-N6-3D5 still showed good NI (Figure 8). The KL-N6-1D4 (R250G) 175 mutation abolished NI of all mAbs to a large degree. The KL-N6-1G9 EMV (R250K) had 176 a lower impact and only caused loss of inhibition by KL-N6-1A5 and KL-N6-1D4 in 177 addition to KL-N6-1G9, likely owing this to its conserved nature. For the KL-N6-2E8 178 EMV (N249S) all mAbs retained some NI activity. The KL-N6-3D5 mutation (P249Q)) 179 had an impact on KL-N6-2E8 and itself, but less so on the other mAbs. Finally, the KL180 N6-3E1 EMV, which carries the same G221E mutation in the NA as the KL-N6-1A5 181 EMV, showed a similar pattern as the KL-N6-1A5 EMV. However, the impact on NI by 182 KL-N6-3E1 was stronger, potentially due to additional mutations in non-NA genes of this 183 EMV which could have contributed to KL-N6-3E1 specific escape. The interdependence 184 of the EMV/mAb combinations makes sense as all escape mutations map to the same 185 patch on the NA (Figure 9). 
188 Lastly, we wanted to determine the protective effect of the isolated mAbs against viral

189 challenge in a mouse model. DBA/2J mice were administered antibody via

190 intraperitoneal route two hours before infection with $5 \mathrm{mg} / \mathrm{kg}$ of $\mathrm{mAb}$ and then

191 challenged intranasally with 5 times the 50\% lethal dose (mLD50) of either

192 A/duck/Czechoslovakia/1956 (H4N6, EAL) or A/Shenzhen/1/2016 (H5N6, EAL). Weight

193 loss and survival was then monitored for 14 days. Protection from

194 A/duck/Czechoslovakia/1956 was variable, with almost no weight loss and no mortality

195 observed with KL-N6-1A5, KL-N6-3C6 and KL-N6-3F10 (Figure 10A and B). KL-N6-

196 1D4, KL-N6-1G9 and KL-N6-3B5 were also protective but mice experienced a transient

197 body weight loss (approximately 10\%). KL-N6-3C7, KL-N6-3D5 and KL-N6-3E1 were

198 less protective against weight loss and for KL-N6-3C7 and KL-N6-3E1 20\% and 40\% of

199 the animals succumbed to infection respectively. No survival benefit was observed for

200 any of the mAbs in the A/Shenzhen/1/2016 challenge model (Figure 10C and D).

\section{Discussion}

203 In this study, we are shedding first light on antigenicity of the N6 NA. As expected, 204 significant cross reactivity exists. This could be due to our immunization regimen which 205 might have favoured cross reactive epitopes but it may also be a consequence of the 206 absence of antigenic drift for most N6 NAs. The characterized mAbs also showed 207 strong $\mathrm{NI}$ activity against isolates from the Eurasian and the North American lineage 208 and protected - to various degrees - against challenge with a historic Eurasian lineage 209 H4N6 strain.

210 However, binding to the N6 of a HPAI H5N6 was suboptimal. Binding to recombinant 211 proteins was only observed for a fraction of the mAbs. Some mAbs that did not bind the 212 recombinant protein but were able to bind cells infected with H5N6 well, suggesting 213 suboptimal folding of the recombinant protein. Nevertheless, most of the mAbs - except 214 KL-N6-3F10, showed negligible NA inhibition activity against H5N6. The lack of 215 functional cross reactivity might suggest that the N6 of H5N6 has experienced more 
216 immune pressure than 'regular' avian isolates, potentially resulting in some antigenic

217 drift.

218 Another feature of this N6 is its truncated stalk. We hypothesized that a longer stalk 219 would maybe make the NA more susceptible to NI by the mAbs but this was only the 220 case for KL-N6-3F10, not for other mAbs. Interestingly, CR9114, an anti-stalk mAb that 221 can exhibit NI through steric hindrance, showed more activity to the H5N6 virus with the 222 truncated stalk than against the version with the long stalk. This also makes sense since 223 a longer stalk displaces the NA enzymatic site further from HA stalk bound mAbs. 224 Disappointingly, none of the mAbs showed protection against H5N6 in a mouse model. 225 Potential explanations could be the higher pathogenicity of H5N6 (even though a 226 A/PR/8/34-based vaccine strain without polybasic cleavage site was used) or the mouse 227 model which lacks complement components. This, paired with lower antibody binding 228 and $\mathrm{NI}$ inhibition likely explains the failure to protect the animals. Of note, the $5 \mathrm{mg} / \mathrm{kg}$ 229 dose, while standard in our laboratory, is relatively low. It is therefore possible that 230 higher doses would have been protective.

231 We also mapped the putative epitopes of six of the mAbs through generating escape 232 mutants. Interestingly, all escape mutations are in close proximity on the lateral surface 233 of the NA. This patch is reminiscent of the binding side of CD6 and other N1 specific 234 and B NA specific antibodies that may span two monomers $(8,13,46)$.

235 While our work provides first insights into the antigenicity of the N6 NA, much more 236 work is needed, especially given that cross reactivity to the N6 of H5N6 was limited and 237 not protective. As such, the N6 NA needs to be further explored and potential antigenic 238 drift mapped. 
243 The viruses A/duck/Wisconsin/480/1979 (H12N6; BEI Resources \# NR-28616), 244 A/redhead/Alberta/192/2002 (H3N6; BEl Resources \# NR-45145), A/duck/England/1956 245 (H11N6; BEl Resources \# NR-21660), A/gull/Maryland/704/1977 (H13N6; BEl 246 Resources \# NR-21663), A/black-legged kittiwake/Quebec/02838-1/2009 (H13N6; BEI 247 Resources \# NR-31217), A/ring-billed gull/Quebec/02434-1/2009 (H13N6; BEI 248 Resources \# NR-31218), A/mallard/Alberta/125/1999 (H11N6; BEl Resources \# NR249 45187), A/blue-winged teal/Illinois/10OS1546/2010 (H3N6; BEl Resources \# NR-35981) 250 and A/blue-winged teal/Wisconsin/402/1983 (H4N6; BEI Resources \# NR-48971) were 251 obtained from the Biodefense and Emerging Infections Research Resources Repository 252 (BEI Resources). The viruses were propagated in 10 day old embryonated chicken 253 eggs (Charles River Laboratories) at $37^{\circ} \mathrm{C}$ for 2 days. The viral titers were determined 254 by conducting a standard plaque assay on Madin-Darby Canine Kidney (MDCK) cells 255 as described earlier (47). The viruses A/duck/Czechoslovakia/1956 (H4N6), $256 \mathrm{~A} /$ Shenzhen/1/2016 (H5N6) and A/swine/Missouri/A01727926/2015 (H4N6) were 257 rescued in the backbone of $A / P R / 8 / 34$ as a 6:2 reassortant, containing the $H A$ and NA 258 segments of the original virus isolates $(41,48)$. Importantly, the H5 HA in the 6:2 $259 \mathrm{~A} / \mathrm{PR} / 8 / 34$ reassortant virus that was generated lacked the polybasic cleavage site.

262 MDCK cells were cultivated in Dulbecco's Modified Eagle's Medium (complete DMEM, 263 Gibco) containing 1\% penicillin/streptomycin (100 U/ml of penicillin, $100 \mu \mathrm{g} / \mathrm{ml}$ 264 streptomycin, Gibco) antibiotic solution, 10\% fetal bovine serum (FBS, Gibco) and 1\% 265 hydroxyethylpiperazine ethane sulfonic acid (HEPES). SP2/0-Ag14 myeloma cells were 266 propagated in complete DMEM supplemented with 1\% L-Glutamine (Gibco).

267 High five cells (BTI-TN-5B1-4, Trichoplusia ni) were grown in serum-free Express Five 268 media (Gibco) containing 1\% L-Glutamine and 1\% penicillin/streptomycin antibiotics 269 mix. Sf9 cells (Spodoptera frugiperda) adapted from the cell line ATCC CRL-1711 were 270 maintained in Trichoplusia ni medium - Fred Hink (TNM-FH, Gemini Bioproducts) 
271 supplemented with 1\% penicillin/streptomycin antibiotics mix, 1\% pluronic F-68 (Sigma-

272 Aldrich) and 10\% fetal bovine serum. In order to passage the baculoviruses, the media

273 was switched to 3\% TNM-FH (1\% penicillin/streptomycin, 1\% pluronic F-68, 3\% FBS).

\section{Recombinant proteins}

276 The recombinant N6 glycoproteins used in this study were expressed in insect cells

277 using the baculovirus expression system. The globular head domain of the respective

278 N6 protein from the strains A/duck/Czechoslovakia/1956 (H4N6), A/Shenzen/1/2016

279 (H5N6), A/swine/Missouri/A01727926/2015 (H4N6), A/Caspian seal/Russia/T1/2012

280 (H4N6) and A/duck/Zhejiang/D9/2013 (H4N6) as well as for the N9 of A/Anhui/1/2013

281 (H7N9) were cloned into a baculovirus shuttle vector, containing a $\mathrm{N}$-terminal signal

282 peptide, followed by a hexahistidine purification tag, a VASP (vasodilator-stimulated

283 phosphoprotein) tetramerization domain and a thrombin cleavage site (49). The

284 baculoviruses were passaged in Sf9 cells to reach higher titers and were then used to

285 infect High-five cells for protein expression. After three days of infection, the soluble

286 proteins were purified from the supernatant, as previously described (50), and were

287 then stored at $-80^{\circ} \mathrm{C}$ for further usage.

289 Enzyme-linked immunosorbent assay (ELISA)

290 Ninety-six well flat bottom plates (Immulon 4 HBX plates, ThermoFisher Scientific) were 291 coated with $50 \mu \mathrm{l} /$ well of $2 \mu \mathrm{g} / \mathrm{ml}$ recombinant protein in $1 \mathrm{x}$ coating buffer (Seracare) at $2924^{\circ} \mathrm{C}$ overnight. The following day, the plate was washed three times with $100 \mu \mathrm{l} /$ well of $2930.1 \%$ Tween 20 (TPBS) to remove residual coating solution and then incubated with $294100 \mu \mathrm{l} /$ well of $3 \%$ milk dissolved in TPBS for $1 \mathrm{~h}$ at room temperature to avoid non295 specific binding. The blocking solution was removed and the primary antibody added at 296 a starting concentration of $30 \mu \mathrm{g} / \mathrm{ml}$ in $1 \%$ milk/TPBS. The antibodies were serially 297 diluted 1:3 and the plates were incubated for 1 hour at room temperature (RT). An anti- 
298 Lassa antibody (KL-AV-1A12 (45)) was included as a negative control and an anti-

299 histidine antibody as a positive control. The plate was then washed three times with 100

$300 \mu \mathrm{l} /$ well TPBS and an anti-mouse secondary antibody (anti-mouse IgG H\&L antibody

301 peroxidase conjugated, Rockland) diluted 1:3000 in 1\% milk/TBPS was added for $1 \mathrm{~h}$ at

302 RT . The plate was washed three times and $100 \mu \mathrm{l} /$ well of SigmaFast o-

303 Phenylenediamine dihydrochloride (OPD) developing solution (Sigma Aldrich) were

304 added. The reaction was stopped after $10 \mathrm{~min}$ incubation at RT with $50 \mu \mathrm{l} /$ well of $3 \mathrm{M}$

305 hydrochloric acid $(\mathrm{HCl})$. The plate was read with a Synergy $\mathrm{H} 1$ hybrid multimode

306 microplate reader (BioTek) at an optical density of $490 \mathrm{~nm}$. The data was analysed by

307 using GraphPad Prism 7 software.

\section{Generation of monoclonal N6-antibodies}

310 Mouse mAbs were produced using hybridoma technology, as previously described (51, 311 52). Briefly, one female 6-8 week old BALB/c mouse (The Jackson Laboratory) was 312 immunized via the intraperitoneal route with $10^{5}$ plaque forming units (PFU)/ml of 313 A/swine/Missouri/A01727926/2015 (H4N6) in $100 \mu \mathrm{l} \mathrm{PBS,} \mathrm{the} \mathrm{same} \mathrm{virus} \mathrm{was} \mathrm{used} 21$

314 days later for an intranasal infection. Three weeks later, the mouse was intranasally 315 infected with a sublethal dose of $10^{3} \mathrm{PFU} / \mathrm{ml}$ of $\mathrm{A} /$ Shenzhen/1/2016 (H5N6) in a volume 316 of $50 \mu \mathrm{l}$. After three weeks, the mouse received a final boost intraperitoneally with 100 $317 \mu \mathrm{g}$ of recombinant N6 protein of A/duck/Zhejiang/D9/2013 (H4N6) adjuvanted with 10 $318 \mu \mathrm{g}$ of poly (I:C) (Invivogen). Three days after the final boost, the mouse was sacrificed 319 and the spleen removed. The spleen was washed with PBS and then flushed with 320 serum-free DMEM (1\% penicillin/streptomycin) to obtain the splenocytes. The 321 splenocytes were fused with SP2/0-Ag14 myeloma cells in a ratio of 5:1 using pre322 warmed polyethylene glycol (PEG; Sigma-Aldrich). The cells were grown on semi-solid 323 selection \& cloning medium with hypoxanthine-aminopterin-thymidine (HAT; Molecular 324 Devices) for 10 days and were then expanded to a 96-well cell culture plate. 
325 To obtain antibody specificity against N6, the supernatant of the individual clones was 326 screened via ELISA against recombinant NA of A/duck/Zhejiang/D9/2013 (H4N6).

327 Reactive clones were tested using the Pierce rapid antibody isotyping kit (Life 328 Technologies). Only IgG heavy-chain subgroups were continuously expanded. The 329 selected hybridoma clones were first expanded in Clonacell-HY Medium E and then 330 constantly switched to Hybridoma SFM media (Gibco) supplemented with 1\% 331 penicillin/streptomycin. The antibodies were then purified as previously described (8).

\section{Immunofluorescence (IF) assay}

334 MDCK cells were seeded in a sterile 96-well cell culture plate at a density of 25,000 335 cells/well using complete DMEM. The next day, cells were infected with a multiplicity of 336 infection (MOI) of 3.0 for 16h using serum free minimal essential media (MEM, Gibco), 337 supplemented with penicillin/streptomycin, HEPES (Gibco), glutamine (200mM L338 Glutamine, Gibco) and sodium bicarbonate (sodium bicarbonate 7.5\% solution, Gibco). 339 The cells were fixed with 3.7\% paraformaldehyde (PFA)/PBS for $1 \mathrm{~h}$ at RT. The plate 340 was the blocked for $1 \mathrm{~h}$ with $3 \%$ milk/PBS. The antibodies were diluted to $30 \mu \mathrm{g} / \mathrm{ml}$ in $1 \%$ 341 milk/PBS and incubated for $1 \mathrm{~h}$ at RT. An anti-Lassa antibody (KL-AV-1A12 (45)) was 342 included as a negative control and CR9114 (42), a broadly cross-reactive HA antibody, 343 as a positive control. The plate was washed three times with 1XPBS and then incubated 344 with a fluorescence goat anti-mouse IgG heavy plus light chain $(\mathrm{H}+\mathrm{L})$-Alexa Fluor 488 345 antibody (Abcam) or an anti-human secondary (Sigma) for CR9114, which were diluted 346 1:1000 in 1\% milk/PBS. The cells were washed with PBS and kept in PBS to avoid 347 drying out during microscopy (Olympus IX-70).

\section{Antibody-dependent cellular cytotoxicity (ADCC) reporter assay}

350 To assess potential ADCC activity of the N6 mAbs the ADCC reporter bioassay kit from 351 Promega was used (53). MDCK cells (25,000 cells/well) were seeded in a white, flat 
352 bottom 96- well cell culture plate (Corning). The following day the cells were washed

353 with PBS and then infected with an $\mathrm{MOI}$ of 1 with the respective virus at $37^{\circ} \mathrm{C}$ for $16 \mathrm{~h}$.

354 On the following day, antibody dilutions were prepared using a start concentration of

$355100 \mu \mathrm{g} / \mathrm{ml}$. The antibodies were serially diluted 1:3 and then added in duplicates to the

356 cells. The human derived monoclonal antibody CR9114 (42) was included as a positive

357 and an irrelevant anti-Lassa virus antibody (KL-AV-1A12 (45)) was used as a negative

358 control. Next, 75,000 effector cells/well were added to the plate and incubated for $6 \mathrm{~h}$ at

$35937^{\circ} \mathrm{C}$. The luciferase substrate was added in the dark and the luminescence activity

360 measured after 5 minutes using a Synergy Hybrid Reader (BioTek). The data was

361 analysed using GraphPad prism 7.

\section{NA inhibition assay}

364 NA inhibition assays were performed as described in detail earlier $(7,54)$. In brief, 96365 well flat bottom Immulon 4 HBX plates (ThermoFisher Scientific) were coated with 150 $366 \mu \mathrm{l} /$ well of fetuin (Sigma Aldrich) at a concentration of $50 \mu \mathrm{g} / \mathrm{ml}$ overnight at $4^{\circ} \mathrm{C}$. The 367 following day, the N6 mAbs were serially diluted 1:3 in PBS with a starting concentration 368 of $30 \mu \mathrm{g} / \mathrm{ml}$. The respective viruses were diluted in PBS at $2 x$ the $50 \%$ effective 369 concentration $\left(\mathrm{EC}_{50}\right)$, which was determined in an NA-assay previously. The virus (75 $370 \mu \mathrm{l} /$ well) was then added to the mAb dilution plate and the virus/mAb mixture was 371 incubated for $1 \mathrm{~h} 45 \mathrm{~min}$ shaking at RT. During this time, the fetuin coated plates were 372 washed 6x with PBST and then blocked with 5\% BSA/PBS for at least $1 \mathrm{~h}$ at RT. After 1 373 hour, the fetuin plates were washed and $100 \mu \mathrm{l}$ of the virus/antibody mixture were 374 added to plates and incubated for $2 \mathrm{~h}$ at $37^{\circ} \mathrm{C}$. The plates were washed and incubated 375 with $5 \mu \mathrm{g} / 100 \mu \mathrm{l} /$ well of PNA for $1 \mathrm{~h} 45 \mathrm{~min}$ in the dark. The plates were then washed and 376 developed by using $100 \mu \mathrm{l} /$ well Sigmafast OPD solution (Sigma Aldrich). After 7 minutes 377 of incubation in the dark, the reaction was stopped by adding $50 \mu \mathrm{l} /$ well of $3 \mathrm{M} \mathrm{HCl}$ and 378 the plates read at an absorbance of $490 \mathrm{~nm}$ using a Synergy $\mathrm{H} 1$ hybrid multimode 
379 microplate reader (BioTek). The $\mathrm{IC}_{50}$ values were calculated by using GraphPad Prism 3807.

382 Plaque reduction neutralization assay

383 Plaque reduction neutralization assays were performed on MDCK cells (300,000 384 cells/well) which were seeded in a sterile 12-well plate the day before. The following 385 day, the mAbs were serially diluted $1: 3$ in $1 \times$ MEM and $50 \mu l$ of $386 \mathrm{~A} /$ duck/Czechoslovakia/1956 (H4N6, $1000 \mathrm{PFU} / \mathrm{ml})$ were added to each dilution and 387 incubated shaking at RT for $1 \mathrm{~h}$. The cells were washed with PBS and the antibody-virus 388 mixture was added for $1 \mathrm{~h}$ at $37^{\circ} \mathrm{C}$. The mixture was then aspirated and the cells 389 overlaid with agar consisting out of minimal essential medium (2xMEM), $2 \%$ Oxoid agar, $3901 \%$ DEAE, TPCK-treated trypsin as well as the respective antibody. The plates were 391 incubated at $37^{\circ} \mathrm{C}$ for 2 days and the cells afterwards fixed with $3.7 \%$ PFA in PBS. The 392 plaques were then visualized by immunostaining. Briefly, the agar-overlay was removed 393 and the plates blocked with 3\% milk/PBS for $1 \mathrm{~h}$ at RT. Afterwards, an antibody-cocktail 394 made out of all ten N6-antibodies diluted 1:3000 in milk/PBS was added and incubated 395 for $2 \mathrm{~h}$ at RT. The plates were washed and incubated with secondary antibody (Anti396 mouse IgG (H\&L) Antibody Peroxidase Conjugated, Rockland) diluted 1:3000 in 1\% 397 milk/PBS for $1 \mathrm{~h}$. The plates were washed and developed by using Trueblue reagent 398 (KPL). The plaque number as well as the plaque size was determined for each antibody 399 dilution and the percent inhibition determined based on a no-antibody control. The data 400 was analysed using GraphPhad Prism $7(54,55)$.

\section{Evaluation of the prophylactic efficacy in mice}

402 To test the prophylactic efficacy of the N6 antibodies, female 6-8 week old DBA/2J mice 403 (The Jackson Laboratory) received an antibody dose of $5 \mathrm{mg} / \mathrm{kg}$ intraperitoneal $(\mathrm{n}=5$ per 404 group). An irrelevant anti-Lassa antibody (KL-AV-1A12 (45)) was given to one of the 405 groups as negative control. Two hours after antibody administration, the mice were 406 anesthetized and intranasally challenged with $5 x \mathrm{mLD}_{50}$ (mouse lethal dose, 50\%) of 
A/duck/Czechoslovakia/1956 (H4N6) or A/Shenzhen/1/2016 (H5N6). Weight loss was

408 monitored over 14 days and any mouse which lost more than $25 \%$ of its initial body

409 weight was sacrificed. Survival and weight loss data were analysed by using GraphPad

410 Prism 7. All animal procedures were performed in accordance with the Icahn School of

411 Medicine at Mount Sinai Institutional Animal Care and Use Committee (IACUC).

\section{Escape mutants}

413 MDCKs were plated at a density of 1,000,000 cells/well in a 6 - well plate the day prior

414 The next day, cells were washed with PBS and infected with an MOI of 1 with the virus

$415 \mathrm{~A} /$ duck/Czechoslovakia/1956 (H4N6) by using 1xMEM as well as $1 \mathrm{ug} / \mathrm{ml}$ TPCK-treated

416 trypsin. The respective mAbs were added at a concentration of $1 \mathrm{xIC}_{50}$ to the virus

417 mixture and the cells then incubated for 2 days at $37^{\circ} \mathrm{C}$. The cell supernatant was

418 collected and used to continue the passaging of the virus. Additionally, to this, the $\mathrm{IC}_{50}$

419 concentration of the mAbs was doubled with every passage. This procedure was

420 repeated until an $I_{50}$ concentration of 128 was reached. The presence of the virus

421 within the samples was confirmed by performing an immunostaining of the cell layer

422 after every passage. The same virus was passaged in parallel completely without mAbs

423 as well as together with an irrelevant antibody (anti-Lassa KL-AV-1A12 (45)), to confirm

424 that no random mutations were acquired over time.

425 Once the last passage was reached, the viruses were plaque purified and injected, 426 together with the respective mAb, in 10-day old embryonated chicken eggs, to 427 propagate the virus. The eggs were incubated for 2 days at $37^{\circ} \mathrm{C}$. RNA was extracted 428 from the allantoic fluid by using the Direct-zol RNA isolation kit from Zymo research. 429 The purified RNA was used to deep-sequence the escape viruses. 
432 This work was supported in part by the National Institute of Allergy and Infectious 433 Disease (NIAID) Centers of Excellence for Influenza Research and Surveillance 434 (CEIRS) contract (HHSN272201400008C).

Conflict of interest statement

437 The authors declare no conflict of interest.

\section{References}

440 1. Liu S, Ji K, Chen J, Tai D, Jiang W, Hou G, Li J, Huang B. 2009. Panorama phylogenetic diversity and distribution of Type A influenza virus. PLoS One 4:e5022.

2. Tong S, Li Y, Rivailler P, Conrardy C, Castillo DA, Chen LM, Recuenco S, Ellison JA, Davis CT, York IA, Turmelle AS, Moran D, Rogers S, Shi M, Tao Y, Weil MR, Tang K, Rowe LA, Sammons S, Xu X, Frace M, Lindblade KA, Cox NJ, Anderson LJ, Rupprecht CE, Donis RO. 2012. A distinct lineage of influenza A virus from bats. Proc Natl Acad Sci U S A 109:4269-74.

3. Tong S, Zhu X, Li Y, Shi M, Zhang J, Bourgeois M, Yang H, Chen X, Recuenco S, Gomez J, Chen LM, Johnson A, Tao Y, Dreyfus C, Yu W, McBride R, Carney PJ, Gilbert AT, Chang J, Guo Z, Davis CT, Paulson JC, Stevens J, Rupprecht CE, Holmes EC, Wilson IA, Donis RO. 2013. New world bats harbor diverse influenza A viruses. PLoS Pathog 9:e1003657.

4. Madsen A, Dai YN, McMahon M, Schmitz AJ, Turner JS, Tan J, Lei T, Alsoussi WB, Strohmeier S, Amor M, Mohammed BM, Mudd PA, Simon V, Cox RJ, Fremont DH, Krammer F, Ellebedy AH. 2020. Human Antibodies Targeting Influenza B Virus Neuraminidase Active Site Are Broadly Protective. Immunity 53:852-863.e7.

5. McMahon M, Strohmeier S, Rajendran M, Capuano C, Ellebedy AH, Wilson PC, Krammer F. 2020. Correctly folded - but not necessarily functional - influenza virus neuraminidase is required to induce protective antibody responses in mice. Vaccine 38:7129-7137.

6. Stadlbauer D, Zhu X, McMahon M, Turner JS, Wohlbold TJ, Schmitz AJ, Strohmeier S, Yu W, Nachbagauer R, Mudd PA, Wilson IA, Ellebedy AH, Krammer F. 2019. Broadly protective human antibodies that target the active site of influenza virus neuraminidase. Science 366:499-504.

7. Wohlbold TJ, Nachbagauer R, Xu H, Tan GS, Hirsh A, Brokstad KA, Cox RJ, Palese P, Krammer F. 2015. Vaccination with Adjuvanted Recombinant Neuraminidase Induces Broad Heterologous, but Not Heterosubtypic, Cross-Protection against Influenza Virus Infection in Mice. MBio 6. 
8. Wohlbold TJ, Podolsky KA, Chromikova V, Kirkpatrick E, Falconieri V, Meade P, Amanat F, Tan J, tenOever BR, Tan GS, Subramaniam S, Palese P, Krammer F. 2017. Broadly protective murine monoclonal antibodies against influenza B virus target highly conserved neuraminidase epitopes. Nat Microbiol 2:1415-1424.

9. Wan H, Gao J, Yang H, Yang S, Harvey R, Chen YQ, Zheng NY, Chang J, Carney PJ, Li X, Plant E, Jiang L, Couzens L, Wang C, Strohmeier S, Wu WW, Shen RF, Krammer F, Cipollo JF, Wilson PC, Stevens J, Wan XF, Eichelberger MC, Ye Z. 2019. The neuraminidase of $\mathrm{A}(\mathrm{H} 3 \mathrm{~N} 2)$ influenza viruses circulating since 2016 is antigenically distinct from the A/Hong Kong/4801/2014 vaccine strain. Nat Microbiol.

10. Krammer F, Fouchier RAM, Eichelberger MC, Webby RJ, Shaw-Saliba K, Wan H, Wilson PC, Compans RW, Skountzou I, Monto AS. 2018. NAction! How Can Neuraminidase-Based Immunity Contribute to Better Influenza Virus Vaccines? MBio 9.

11. Chen YQ, Wohlbold TJ, Zheng NY, Huang M, Huang Y, Neu KE, Lee J, Wan H, Rojas KT, Kirkpatrick E, Henry C, Palm AE, Stamper CT, Lan LY, Topham DJ, Treanor J, Wrammert J, Ahmed R, Eichelberger MC, Georgiou G, Krammer F, Wilson PC. 2018. Influenza Infection in Humans Induces Broadly Cross-Reactive and Protective Neuraminidase-Reactive Antibodies. Cell 173:417-429.e10.

12. Powell H, Pekosz A. 2020. Neuraminidase antigenic drift of H3N2 clade 3c.2a viruses alters virus replication, enzymatic activity and inhibitory antibody binding. PLoS Pathog 16:e1008411.

13. Yasuhara A, Yamayoshi S, Kiso M, Sakai-Tagawa Y, Koga M, Adachi E, Kikuchi T, Wang IH, Yamada S, Kawaoka Y. 2019. Antigenic drift originating from changes to the lateral surface of the neuraminidase head of influenza A virus. Nat Microbiol 4:10241034.

14. Wan H, Gao J, Xu K, Chen H, Couzens LK, Rivers KH, Easterbrook JD, Yang K, Zhong L, Rajabi M, Ye J, Sultana I, Wan XF, Liu X, Perez DR, Taubenberger JK, Eichelberger MC. 2013. Molecular Basis for Broad Neuraminidase Immunity: Conserved Epitopes in Seasonal and Pandemic H1N1 as Well as H5N1 Influenza Viruses. J Virol 87:9290-300.

15. Zhu X, Turner HL, Lang S, McBride R, Bangaru S, Gilchuk IM, Yu W, Paulson JC, Crowe JE, Ward AB, Wilson IA. 2019. Structural Basis of Protection against H7N9 Influenza Virus by Human Anti-N9 Neuraminidase Antibodies. Cell Host Microbe 26:729-738.e4.

16. Tulip WR, Varghese JN, Laver WG, Webster RG, Colman PM. 1992. Refined crystal structure of the influenza virus N9 neuraminidase-NC41 Fab complex. J Mol Biol 227:122-48.

17. Gilchuk IM, Bangaru S, Gilchuk P, Irving RP, Kose N, Bombardi RG, Thornburg NJ, Creech CB, Edwards KM, Li S, Turner HL, Yu W, Zhu X, Wilson IA, Ward AB, Crowe JE. 2019. Influenza H7N9 Virus Neuraminidase-Specific Human Monoclonal Antibodies Inhibit Viral Egress and Protect from Lethal Influenza Infection in Mice. Cell Host Microbe 26:715-728.e8.

18. Nuss JM, Whitaker PB, Air GM. 1993. Identification of critical contact residues in the NC41 epitope of a subtype N9 influenza virus neuraminidase. Proteins 15:121-32.

19. Lee JT, Air GM. 2002. Contacts between influenza virus N9 neuraminidase and monoclonal antibody NC10. Virology 300:255-68. 
20. Wan H, Qi L, Gao J, Couzens LK, Jiang L, Gao Y, Sheng ZM, Fong S, Hahn M, Khurana S, Taubenberger JK, Eichelberger MC. 2018. Comparison of the Efficacy of N9 Neuraminidase-Specific Monoclonal Antibodies against Influenza A(H7N9) Virus Infection. J Virol 92.

21. Kayed AS, Kandeil A, Gomaa MR, El-Shesheny R, Mahmoud S, Hegazi N, Fayez M, Sheta B, McKenzie PP, Webby RJ, Kayali G, Ali MA. 2019. Surveillance for avian influenza viruses in wild birds at live bird markets, Egypt, 2014-2016. Influenza Other Respir Viruses 13:407-414.

22. Yu Z, Gao X, Wang T, Li Y, Xu Y, Chu D, Sun H, Wu C, Li S, Wang H, Xia Z, Lin W, Qian J, Chen H, Xia X, Gao Y. 2015. Fatal H5N6 Avian Influenza Virus Infection in a Domestic Cat and Wild Birds in China. Sci Rep 5:10704.

23. Yuan R, Zou L, Kang Y, Wu J, Zeng X, Lu J, Liang L, Song Y, Zhang X, Ni H, Lin J, Liao M, Ke C. 2016. Reassortment of Avian Influenza A/H6N6 Viruses from Live Poultry Markets in Guangdong, China. Front Microbiol 7:65.

24. Venkatesh D, Poen MJ, Bestebroer TM, Scheuer RD, Vuong O, Chkhaidze M, Machablishvili A, Mamuchadze J, Ninua L, Fedorova NB, Halpin RA, Lin X, Ransier A, Stockwell TB, Wentworth DE, Kriti D, Dutta J, van Bakel H, Puranik A, Slomka MJ, Essen S, Brown IH, Fouchier RAM, Lewis NS. 2018. Avian Influenza Viruses in Wild Birds: Virus Evolution in a Multihost Ecosystem. J Virol 92.

25. Karasin AI, Brown IH, Carman S, Olsen CW. 2000. Isolation and characterization of H4N6 avian influenza viruses from pigs with pneumonia in Canada. J Virol 74:9322-7.

26. Li X, Fu Y, Yang J, Guo J, He J, Weng S, Jia Y, Liu B, Zhu Q, Chen H. 2015. Genetic and biological characterization of two novel reassortant H5N6 swine influenza viruses in mice and chickens. Infect Genet Evol 36:462-466.

27. Zhang G, Kong W, Qi W, Long LP, Cao Z, Huang L, Qi H, Cao N, Wang W, Zhao F, Ning Z, Liao M, Wan XF. 2011. Identification of an H6N6 swine influenza virus in southern China. Infect Genet Evol 11:1174-7.

28. Krumbholz A, Lange J, Sauerbrei A, Groth M, Platzer M, Kanrai P, Pleschka S, Scholtissek C, Büttner M, Dürrwald R, Zell R. 2014. Origin of the European avian-like swine influenza viruses. J Gen Virol 95:2372-2376.

29. Runstadler J, Hill N, Hussein IT, Puryear W, Keogh M. 2013. Connecting the study of wild influenza with the potential for pandemic disease. Infect Genet Evol 17:162-87.

30. Zhao Z, Liu L, Guo Z, Zhang C, Wang Z, Wen G, Zhang W, Shang Y, Zhang T, Jiao Z, Chen L, Cui H, Jin M, Wang C, Luo Q, Shao H. 2019. A Novel Reassortant Avian H7N6 Influenza Virus Is Transmissible in Guinea Pigs via Respiratory Droplets. Front Microbiol 10:18.

31. Choi WS, Jeong JH, Kwon JJ, Ahn SJ, Lloren KKS, Kwon HI, Chae HB, Hwang J, Kim MH, Kim CJ, Webby RJ, Govorkova EA, Choi YK, Baek YH, Song MS. 2018. Screening for Neuraminidase Inhibitor Resistance Markers among Avian Influenza Viruses of the N4, N5, N6, and N8 Neuraminidase Subtypes. J Virol 92.

32. Stoner TD, Krauss S, Turner JC, Seiler P, Negovetich NJ, Stallknecht DE, Frase S, Govorkova EA, Webster RG. 2012. Susceptibility of avian influenza viruses of the N6 subtype to the neuraminidase inhibitor oseltamivir. Antiviral Res 93:322-9. 
33. Kwon HI, Kim YI, Park SJ, Kim EH, Kim S, Si YJ, Song MS, Pascua PNQ, Govorkova EA, Webster RG, Webby RJ, Choi YK. 2019. A Novel Neuraminidase-Dependent Hemagglutinin Cleavage Mechanism Enables the Systemic Spread of an H7N6 Avian Influenza Virus. mBio 10.

34. Lee DH, Bertran K, Kwon JH, Swayne DE. 2017. Evolution, global spread, and pathogenicity of highly pathogenic avian influenza H5Nx clade 2.3.4.4. J Vet Sci 18:269280.

35. WHO. 2020. Avian Influenza Weekly Update Number 772, https://www.who.int/docs/default-source/wpro--documents/emergency/surveillance/avian-influenza/ai20201218.pdf?sfvrsn=30d65594_90.

36. Bi Y, Tan S, Yang Y, Wong G, Zhao M, Zhang Q, Wang Q, Zhao X, Li L, Yuan J, Li H, Xu W, Shi W, Quan C, Zou R, Li J, Zheng H, Yang L, Liu WJ, Liu D, Wang H, Qin Y, Liu L, Jiang C, Liu W, Lu L, Gao GF, Liu Y. 2019. Clinical and Immunological Characteristics of Human Infections With H5N6 Avian Influenza Virus. Clin Infect Dis 68:1100-1109.

37. Li T, Ma Y, Li K, Tang X, Wang M, Yang Z. 2016. Death of a very young child infected with influenza A (H5N6). J Infect 73:626-627.

38. Shen YY, Ke CW, Li Q, Yuan RY, Xiang D, Jia WX, Yu YD, Liu L, Huang C, Qi WB, Sikkema R, Wu J, Koopmans M, Liao M. 2016. Novel Reassortant Avian Influenza A(H5N6) Viruses in Humans, Guangdong, China, 2015. Emerg Infect Dis 22:1507-9.

39. He J, Duan J. 2015. First human case of avian influenza A (H5N6) in Yunnan province, China. SAGE Open Med Case Rep 3:2050313X15596484.

40. Yang ZF, Mok CK, Peiris JS, Zhong NS. 2015. Human Infection with a Novel Avian Influenza A(H5N6) Virus. N Engl J Med 373:487-9.

41. Amanat F, Meade P, Strohmeier S, Krammer F. 2019. Cross-reactive antibodies binding to $\mathrm{H} 4$ hemagglutinin protect against a lethal H4N6 influenza virus challenge in the mouse model. Emerg Microbes Infect 8:155-168.

42. Dreyfus C, Laursen NS, Kwaks T, Zuijdgeest D, Khayat R, Ekiert DC, Lee JH, Metlagel Z, Bujny MV, Jongeneelen M, van der Vlugt R, Lamrani M, Korse HJ, Geelen E, Sahin Ö, Sieuwerts M, Brakenhoff JP, Vogels R, Li OT, Poon LL, Peiris M, Koudstaal W, Ward AB, Wilson IA, Goudsmit J, Friesen RH. 2012. Highly conserved protective epitopes on influenza B viruses. Science 337:1343-8.

43. Chromikova V, Zaragoza MA, Krammer F. 2017. Generation of a serum free CHO DG44 cell line stably producing a broadly protective anti-influenza virus monoclonal antibody. PLoS One 12:e0183315.

44. Rajendran M, Nachbagauer R, Ermler ME, Bunduc P, Amanat F, Izikson R, Cox M, Palese P, Eichelberger M, Krammer F. 2017. Analysis of Anti-Influenza Virus Neuraminidase Antibodies in Children, Adults, and the Elderly by ELISA and Enzyme Inhibition: Evidence for Original Antigenic Sin. MBio 8.

45. Amanat F, Duehr J, Oestereich L, Hastie KM, Ollmann Saphire E, Krammer F. 2018. Antibodies to the Glycoprotein GP2 Subunit Cross-React between Old and New World Arenaviruses. mSphere 3 . 
46. Wan H, Yang H, Shore DA, Garten RJ, Couzens L, Gao J, Jiang L, Carney PJ, Villanueva J, Stevens J, Eichelberger MC. 2015. Structural characterization of a protective epitope spanning $\mathrm{A}(\mathrm{H} 1 \mathrm{~N} 1)$ pdm09 influenza virus neuraminidase monomers. Nat Commun 6:6114.

47. Klausberger M, Wilde M, Palmberger D, Hai R, Albrecht RA, Margine I, Hirsh A, García-Sastre A, Grabherr R, Krammer F. 2014. One-shot vaccination with an insect cellderived low-dose influenza A H7 virus-like particle preparation protects mice against H7N9 challenge. Vaccine 32:355-62.

48. Hai R, Krammer F, Tan GS, Pica N, Eggink D, Maamary J, Margine I, Albrecht RA, Palese P. 2012. Influenza viruses expressing chimeric hemagglutinins: globular head and stalk domains derived from different subtypes. J Virol 86:5774-81.

49. Krammer F, Margine I, Tan GS, Pica N, Krause JC, Palese P. 2012. A carboxy-terminal trimerization domain stabilizes conformational epitopes on the stalk domain of soluble recombinant hemagglutinin substrates. PLoS One 7:e43603.

50. Margine I, Palese P, Krammer F. 2013. Expression of Functional Recombinant Hemagglutinin and Neuraminidase Proteins from the Novel H7N9 Influenza Virus Using the Baculovirus Expression System. J Vis Exp.

51. Tan GS, Lee PS, Hoffman RM, Mazel-Sanchez B, Krammer F, Leon PE, Ward AB, Wilson IA, Palese P. 2014. Characterization of a broadly neutralizing monoclonal antibody that targets the fusion domain of group 2 influenza a virus hemagglutinin. $\mathrm{J}$ Virol 88:13580-92.

52. Wohlbold TJ, Chromikova V, Tan GS, Meade P, Amanat F, Comella P, Hirsh A, Krammer F. 2015. Hemagglutinin Stalk- and Neuraminidase-Specific Monoclonal Antibodies Protect against Lethal H10N8 Influenza Virus Infection in Mice. J Virol 90:851-61.

53. Asthagiri Arunkumar G, Ioannou A, Wohlbold TJ, Meade P, Aslam S, Amanat F, Ayllon J, García-Sastre A, Krammer F. 2019. Broadly Cross-Reactive, Nonneutralizing Antibodies against Influenza B Virus Hemagglutinin Demonstrate Effector FunctionDependent Protection against Lethal Viral Challenge in Mice. J Virol 93.

54. Wohlbold TJ, Chromikova V, Tan GS, Meade P, Amanat F, Comella P, Hirsh A, Krammer F. 2015. Hemagglutinin stalk- and neuraminidase-specific monoclonal antibodies protect against lethal H10N8 influenza virus infection in mice. J Virol.

55. Tan GS, Krammer F, Eggink D, Kongchanagul A, Moran TM, Palese P. 2012. A pan-h1 anti-hemagglutinin monoclonal antibody with potent broad-spectrum efficacy in vivo. J Virol 86:6179-88.

\section{Table 1: Monoclonal antibodies characterized in this study and their IgG subtypes}




\begin{tabular}{|c|c|}
\hline KL-N6-1A5 & $\lg G 2 a$ \\
\hline KL-N6-1D4 & $\lg G 2 a$ \\
\hline KL-N6-1G9 & $\lg G 2 a$ \\
\hline KL-N6-2E8 & $\lg G 2 a$ \\
\hline KL-N6-3B5 & $\lg G 2 a$ \\
\hline KL-N6-3C6 & $\lg G 2 a$ \\
\hline KL-N6-3C7 & $\lg G 2 a$ \\
\hline KL-N6-3D5 & $\lg G 2 a$ \\
\hline KL-N6-3E1 & $\lg G 2 a$ \\
\hline KL-N6-3F10 & $\lg$ G2a \\
\hline
\end{tabular}

638 Figure 1. Phylogenetic tree of the N6 subtype based on amino acid sequences. A 639 phylogenetic tree was constructed based on the amino acid sequence alignment of the 640 various N6 NAs. N9 was used as an outgroup and the scale bar represents a 3\% 641 change in amino acid sequence. Eurasian and North American lineages are indicated. 642 The tree was constructed in Clustal Omega and visualized in FigTree.

644 Figure 2. Murine N6 NA mAbs are highly specific to the N6 subtype and show broad cross-reactivity to both Eurasian and North American lineage NAs via

646 ELISA. Binding of murine N6 NA mAbs against A/swine/Missouri/A01727926/2015 (A), 647 A/duck/Zhejiang/D9/2013 $\quad$ (B), A/Caspian seal/Russia/T1/2012 $\quad$ (C) and 648 A/Shenzhen/1/2016 $($ D) N6 NA recombinant proteins. Binding of murine N6 NA mAbs 649 against A/Anhui/1/2013 (E) N9 NA recombinant protein. None of the antibodies showed 650 reactivity against recombinant N9 protein, which is the closest related NA to N6. An anti651 his-tag antibody was used as a positive control and an irrelevant anti-Lassa antibody 652 (KL-AV-1A12) was used as a negative control. 
654 Figure 3. Murine N6 NA mAb binding to Eurasian lineage virus infected MDCK

655 cells. MDCK cells were infected at a multiplicity of infection (MOI) of 3 with Eurasian 656 lineage viruses and incubated for 16h. The infected cells were then fixed and the N6 $657 \mathrm{mAbs}$ were added at a concentration of $30 \mathrm{ug} / \mathrm{mL}$. Most mAbs showed broad cross 658 reactivity, except against A/Shenzhen/1/2016, were only 8 out of $10 \mathrm{mAbs}$ show 659 binding. MAb CR9114 was used as positive control and an anti-Lassa antibody KL-AV6601 A12 as negative control.

Figure 4. Murine N6 NA mAb binding of North American lineage virus infected MDCK cells. MDCK cells were infected at a multiplicity of infection of 3 with North American lineage viruses and incubated for $16 \mathrm{~h}$. The infected cells were then fixed and the N6 mAbs were added at a concentration of $30 \mathrm{ug} / \mathrm{mL}$. The N6 mAbs show broad cross reactivity within the subset of North American lineage viruses. MAb CR9114 was used as positive control and an anti-Lassa antibody KL-AV-1A12 as negative control.

Figure 5. N6 mAbs strongly inhibit NA enzymatic activity. N6 NA mAbs were tested for inhibition of A/duck/Czechoslovakia/1956 (H4N6)

671 A/swine/Missouri/A01727926/2015 (H4N6) (B), A/Shenzhen/1/2016 (H5N6, low path 6:2 672 A/PR/8/34 reassortant lacking the polybasic cleavage site) (C) and A/Shenzhen/1/2016 673 with an extended N6 stalk domain (D) in the NA inhibition assay. The broad HA stalk 674 antibody CR9114 was used as a positive control (steric hindrance-based NA inhibition) 675 and an irrelevant anti-Lassa antibody KL-AV-1A12 was used as negative control.

677 Figure 6. In vitro functional characterization of the N6 mAbs. (A) Plaque size and 678 (B) number reduction measured via a plaque reduction neutralization assay. (C-E) 679 ADCC reporter activity of mAbs using infected MDCK cells as the substrate. 
680 Luminescence was measured at the end of the assay to assess ADCC activity. The HA 681 stalk antibody CR9114 was used as a positive control and an irrelevant anti-Lassa 682 antibody KL-AV-1A12 as negative control.

Figure 7. MAbs show diminished or knocked out NA inhibition against escape mutants. (A,D and F) Antibodies KL-N6-1A5, KL-N6-2E8 and KL-N6-3E1 show decreased neuraminidase inhibition activity to the respective escape mutant viruses (EMVs). EMV 1A5 and EMV 3E1 share the same mutation at position 221 (G221E), whereas EMV 2E8 has a mutation at position 249 (N249S). (B,C,E) KL-N6-1D4, KL-N6$1 \mathrm{G9}$ and KL-N6-3D5 display a complete loss in neuraminidase inhibition activity against the respective EMVs. EMV 1D4 and EMV 1 G9 share a mutation at the same position at aa 250 (R250G, R250K). EMV 3D5 has a mutation at position 246 (P246Q).

Figure 8. Cross-mAb NA inhibition testing of EMVs. (A) 1A5 EMV (G221E) strongly reduces NI of KL-N6-1D4 and KL-N6-1G9, whereas the inhibition capability of KL-N62E8 and KL-N6-3D5 fully remains. (B) 1D4 EMV (R250G) abolishes NI of all mAbs to a large degree. (C) 1 G9 EMV (R250K) causes total loss of inhibition by KL-N6-1A5 and KL-N6-1D4. (D) 2E8 EMV (N249S) does not strongly impact NI inhibition. (E) 3D5 EMV (P249Q) leads to a decreased NI by KL-N6-2E8 but has lass impact on the remaining mAbs. (F) 3E1 EMV (G221) shows a similar pattern as 1A5 EMV. As a positive control

700 the broad HA stalk antibody CR9114 was used. The negative control was anti-Lassa 701 GP mAb KL-AV-1A12.

703 Figure 9. Visualization of N6 NA mAb escape mutations. The tetrameric protein of 704 A/duck/England/1/1956 (H4N6, PDB 1V0Z) is shown in top down, bottom up and side 705 view, one of the monomers is highlighted in light grey. The individual mutations are 
706 highlighted in different colours and are in close proximity on the lateral surface of the 707 NA.

708

709 Figure 10. In vivo challenge study after prophylactic mAb treatment. N6 NA mAbs

710 were administered to mice at a concentration of $5 \mathrm{mg} / \mathrm{kg}$ two hours prior to challenge.

711 An irrelevant anti-Lassa antibody (KL-AV-1A12) was given as a negative control. Two

712 hours after mAb administration, mice were challenged with $5 \times D_{50}$ of

$713 \mathrm{~A} /$ duck/Czechoslovakia/1956 (H4N6) or A/Shenzhen/1/2016 (H5N6, low path 6:2

714 A/PR/8/34 reassortant lacking the polybasic cleavage site). Morbidity (A) and mortality

715 (B) following A/duck/Czechoslovakia/1956 (H4N6) challenge. Morbidity (C) and mortality

716 (D) following A/Shenzhen/1/2016 (H5N6, low path 6:2 A/PR/8/34 reassortant lacking the 717 polybasic cleavage site) challenge. 


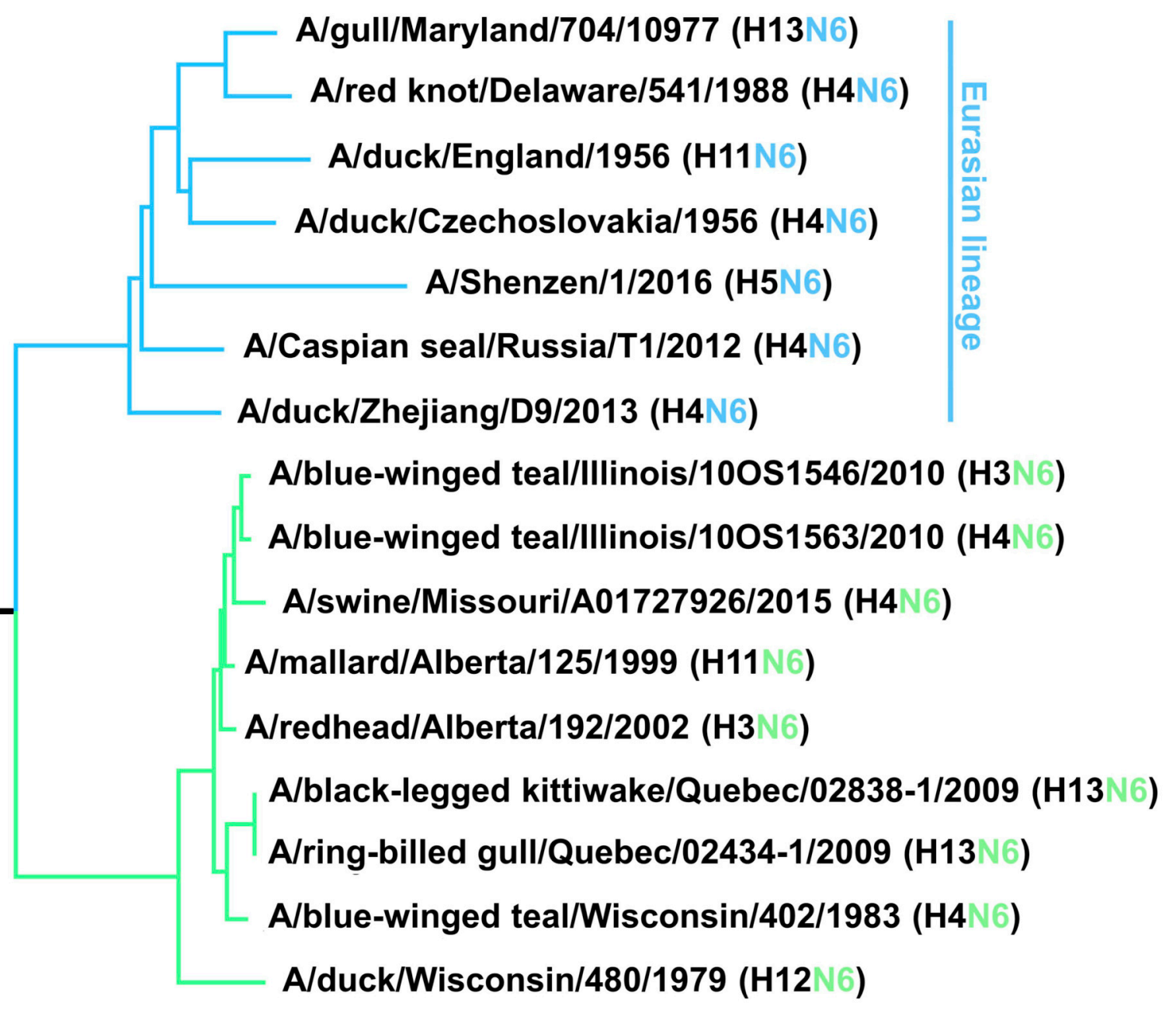

A/Hong Kong/125/2017 (H7N9) 
B

ELISA A/swine/Missouri/A01727926/2015(N6)

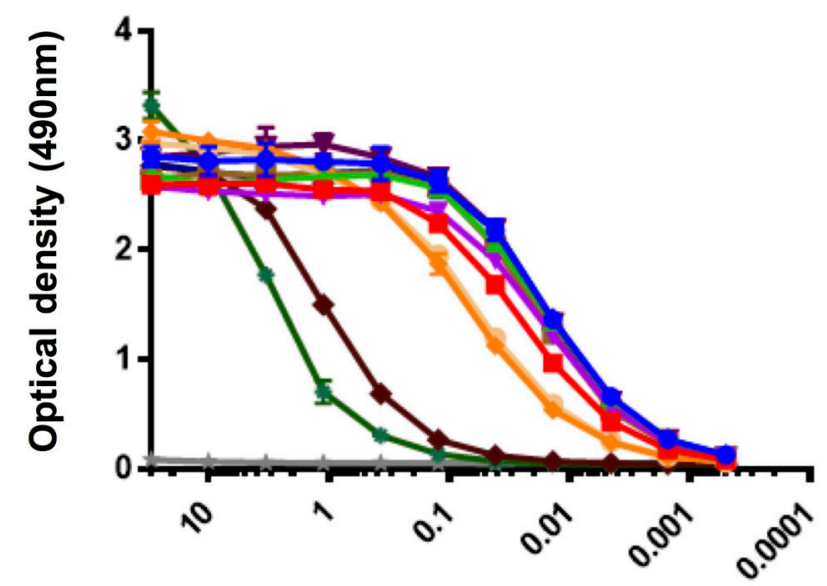

mAb concentration ( $\mu \mathrm{g} / \mathrm{ml})$

D

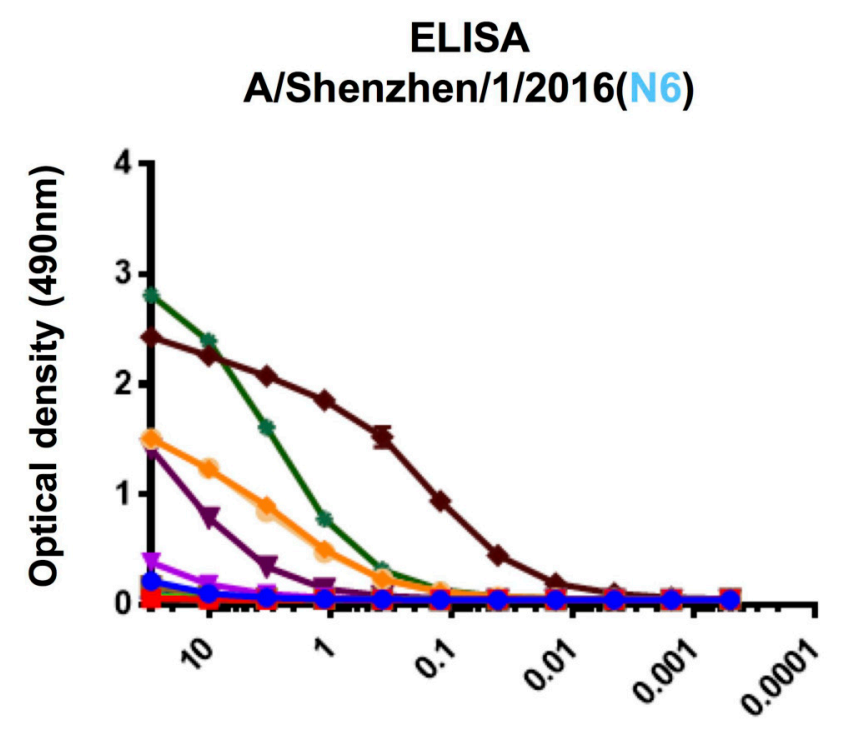

mAb concentration ( $\mu \mathrm{g} / \mathrm{ml})$
ELISA A/duck/Zhejiang/D9/2013(N6)

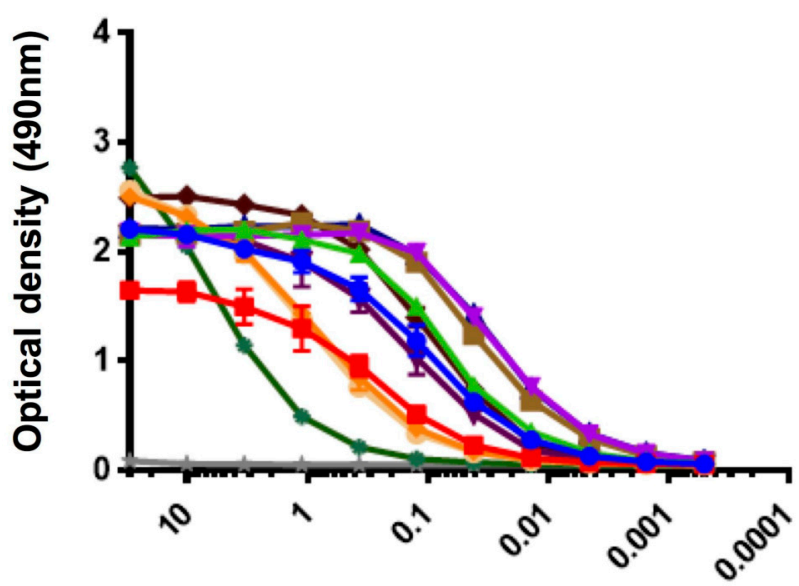

mAb concentration $(\mu \mathrm{g} / \mathrm{ml})$

E

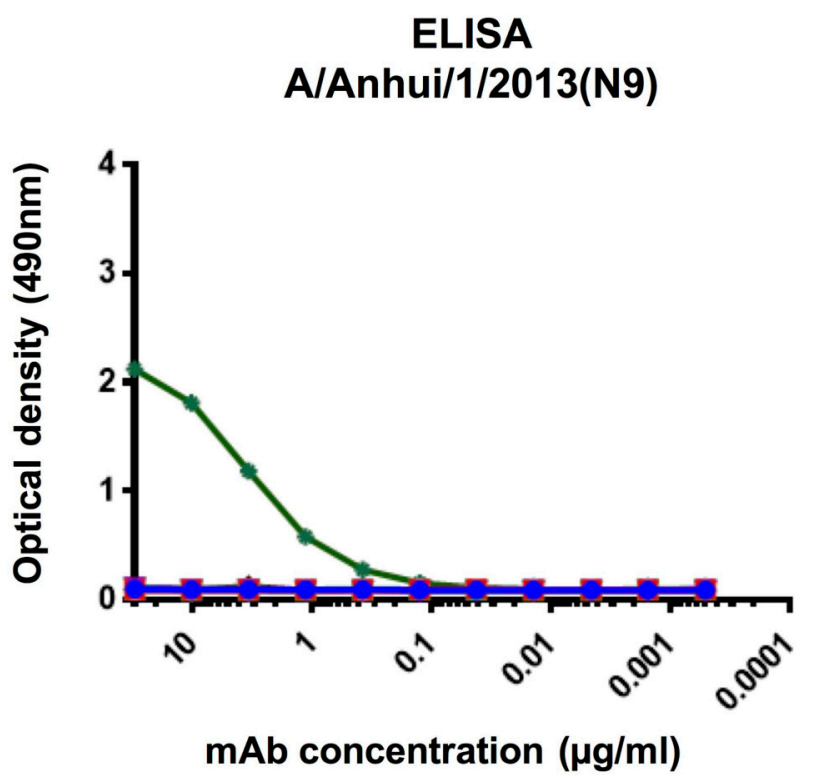

ELISA

A/Caspian seal/Russia/T1/2012(N6)

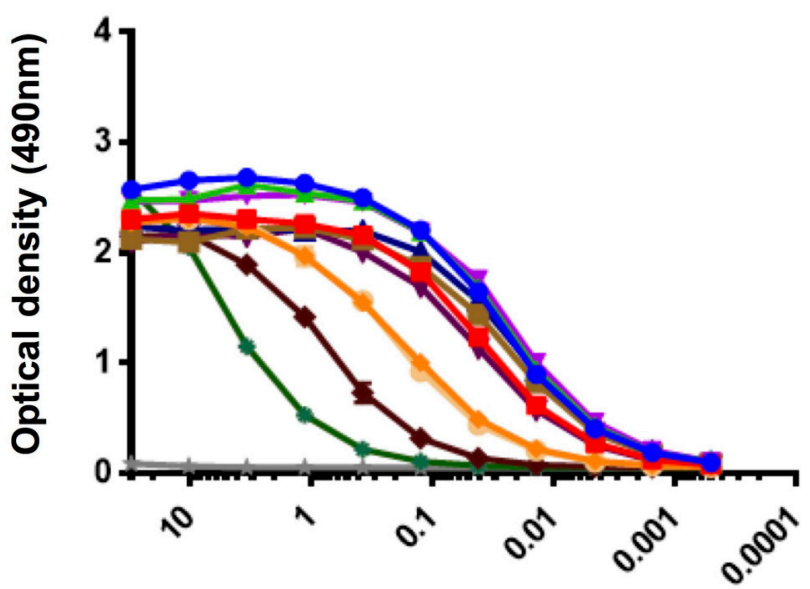

mAb concentration $(\mu \mathrm{g} / \mathrm{ml})$

$\rightarrow \mathrm{KL}-\mathrm{N} 6-1 \mathrm{~A} 5$

$\rightarrow \mathrm{KL}-\mathrm{N6} 6-1 \mathrm{D} 4$

$\leftarrow$ KL-N6-1G9

$\rightarrow$ KL-N6-2E8

$\rightarrow \mathrm{KL}-\mathrm{N} 6-3 \mathrm{~B} 5$

$-\mathrm{KL}-\mathrm{N} 6-3 \mathrm{C6}$

$-\mathrm{KL}-\mathrm{N} 6-3 \mathrm{C} 7$

- KL-N6-3D5

$\rightarrow$ KL-N6-3E1

$\multimap \mathrm{KL}-\mathrm{N} 6-3 \mathrm{~F} 10$

- Pos. Ctrl.

- Neg. Ctrl. 
bioRxiv preprint doi: https://doi.org/10.1101/2021.02 15.431355; this version posted February 16, 2021. The copyright holder for this preprint (which was not certified by peer review) is the author/funder, who has granted bioRxiv a license to display the preprint in perpetuity. It is made available under aCC-BY-NC-ND 4.0 International license.

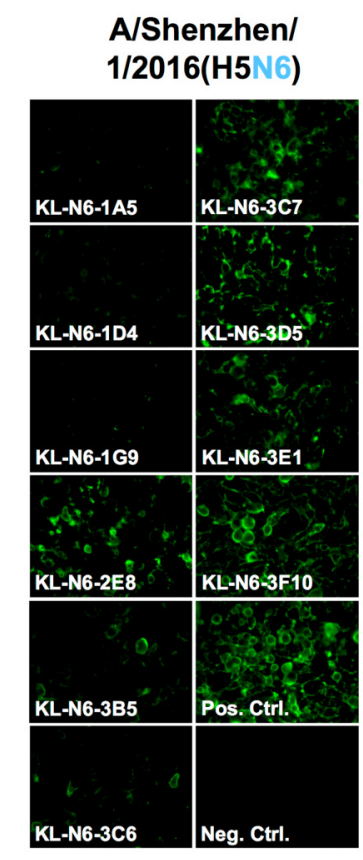

A/gull/Maryland/ 704/1977 (H13N6)

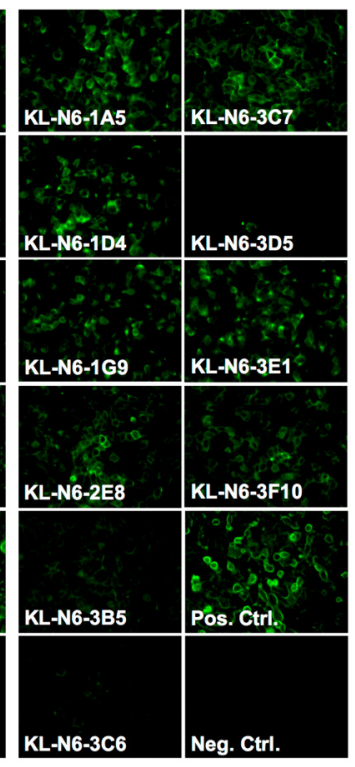

A/redknot/Delaware/ 541/1988 (H4N6)
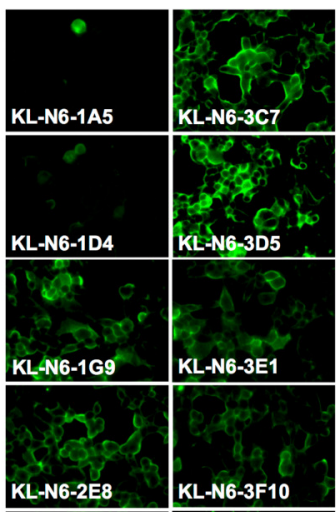

\begin{tabular}{l|l} 
KL-N6-2E8 & KL-N6-3F10 \\
\hline
\end{tabular}

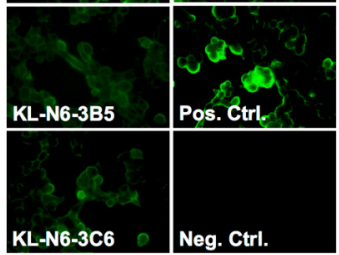

A/duck/England/ A/duck/Czechoslovakia/ 1956 (H11 N6)

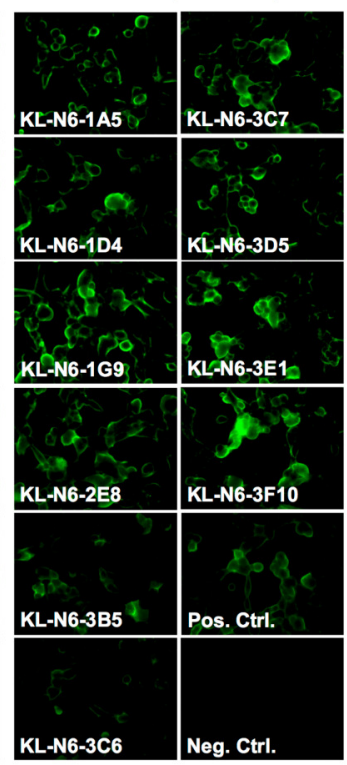

1956(H4N6)

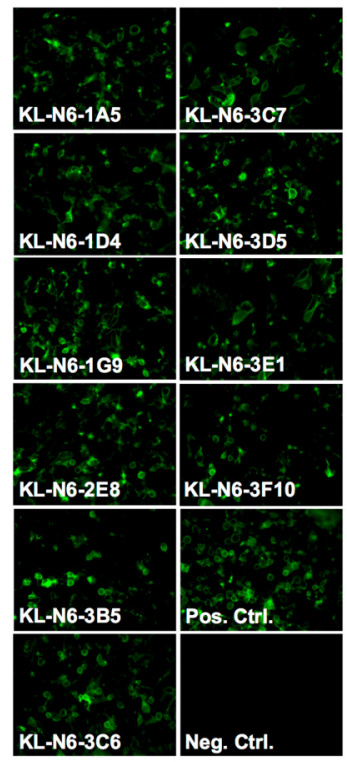

A/duck/Zhejiang/ D9/2013(H4N6)

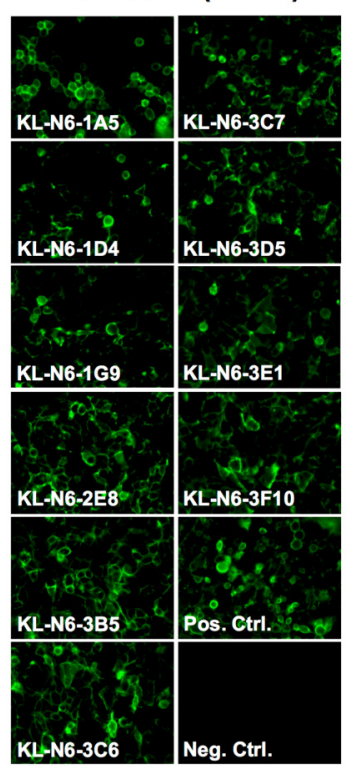


A/mallard/Albertal 125/1999 (H11N6)

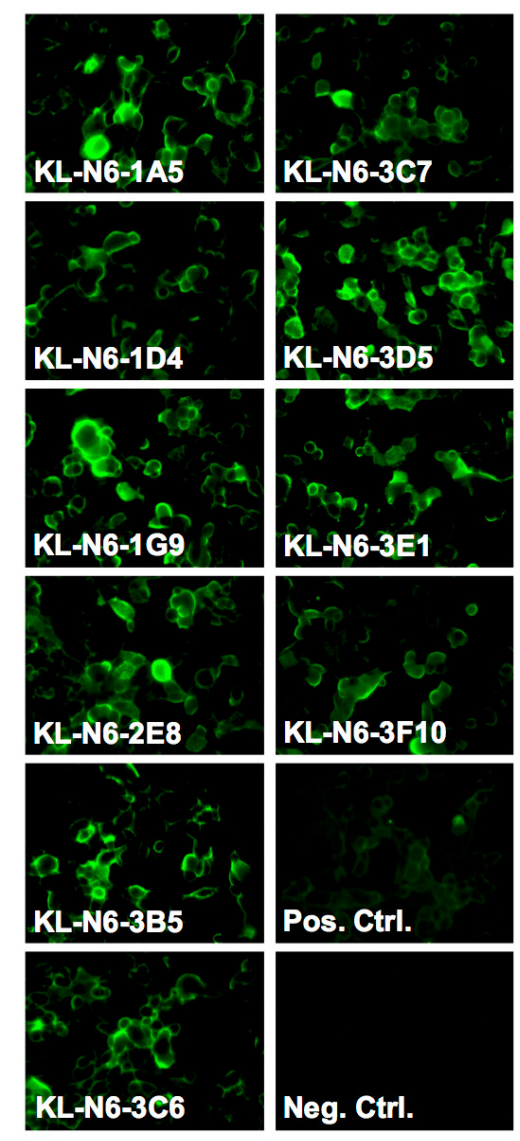

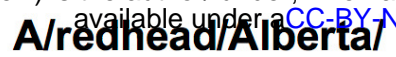
192/2002 (H3N6)

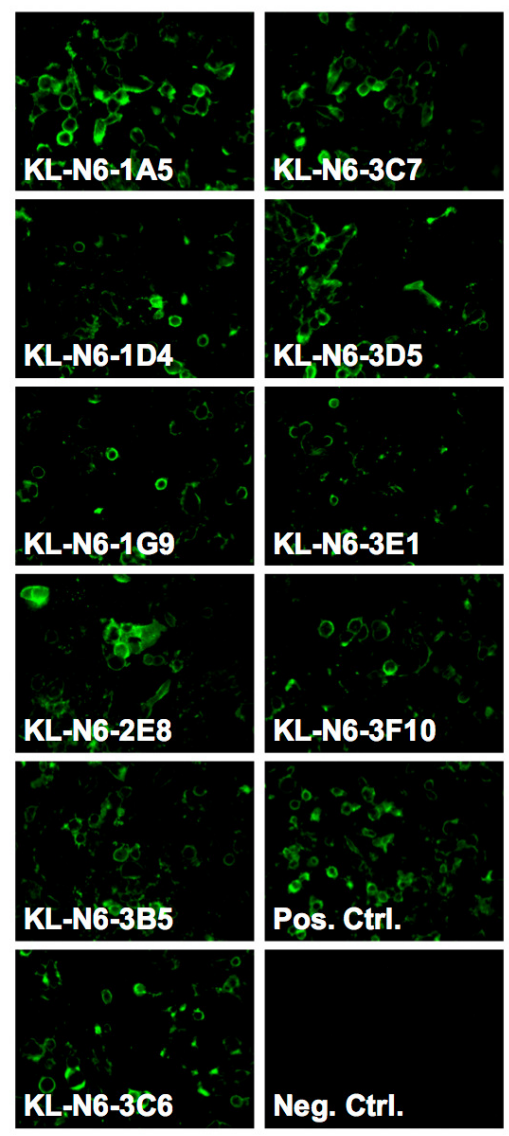
A01727926/2015 (H4 NG)
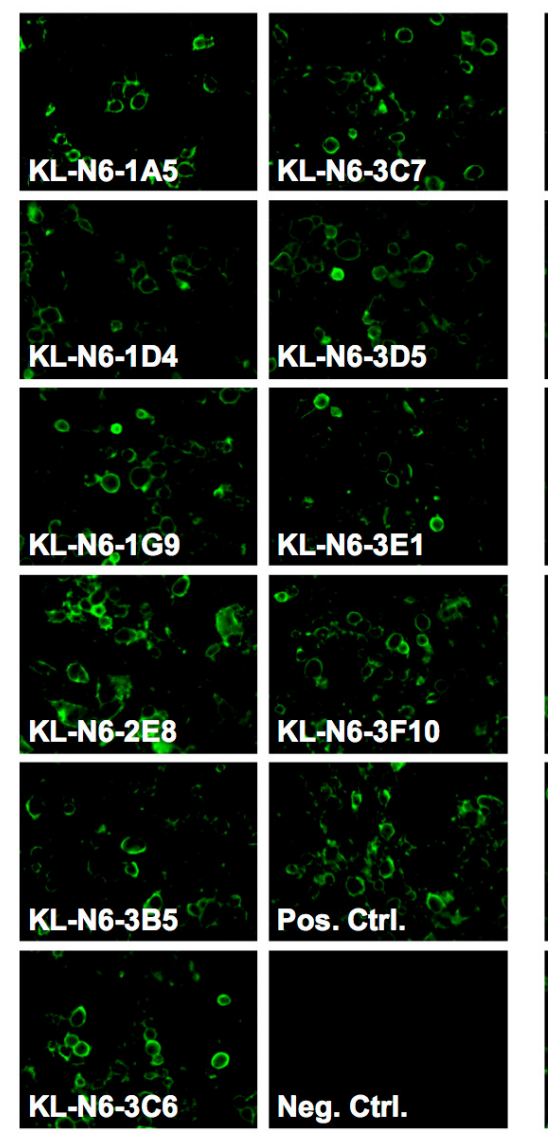
teal/IIlinois/ 100S1546/2010 (H3 N6)

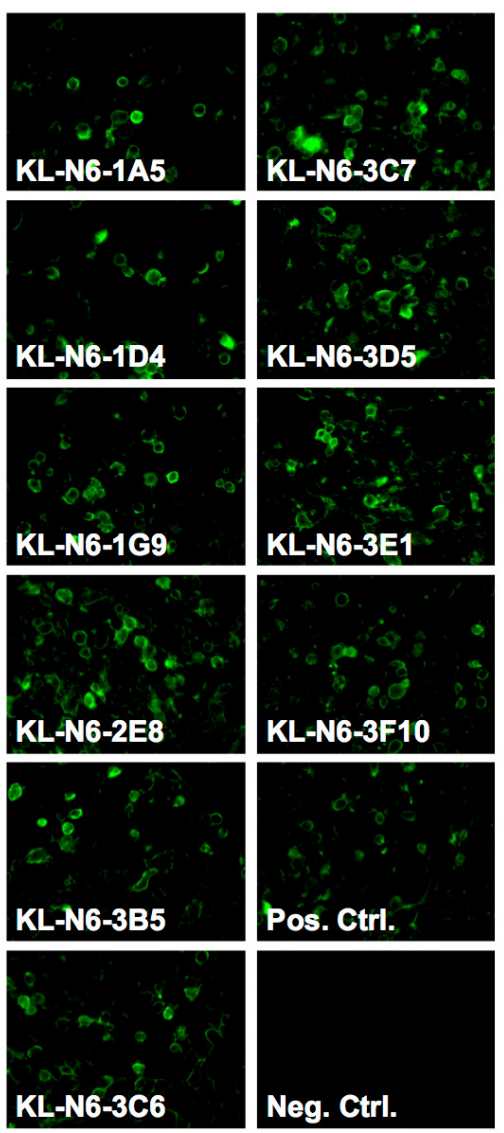

A/blue-winged teal/Illinois/ 100S1563/2010 (H4N6)

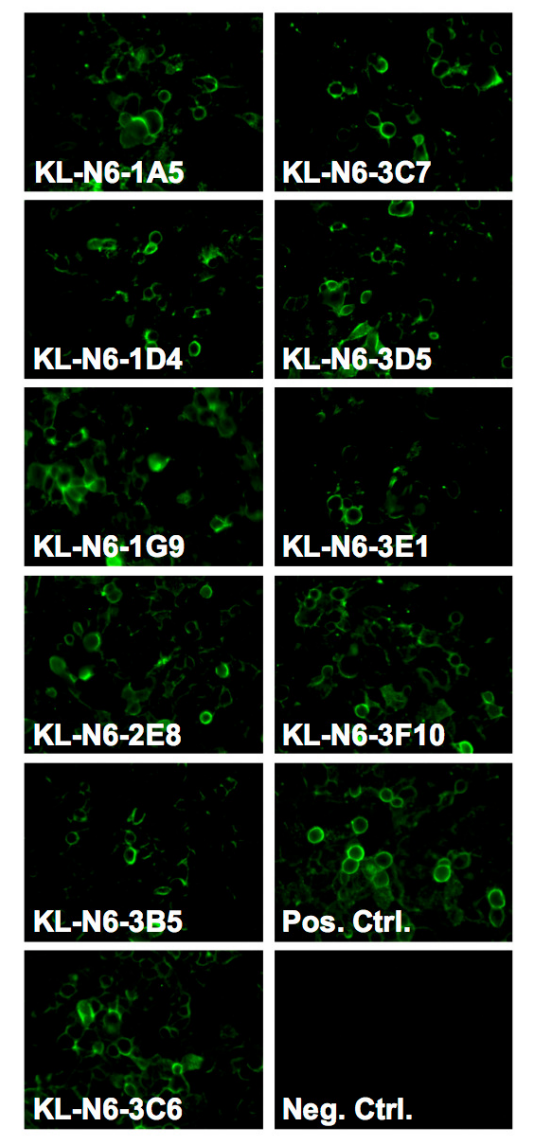

A/ring-billed gull/Quebec/ 02434-1/2009 (H13 6$)$

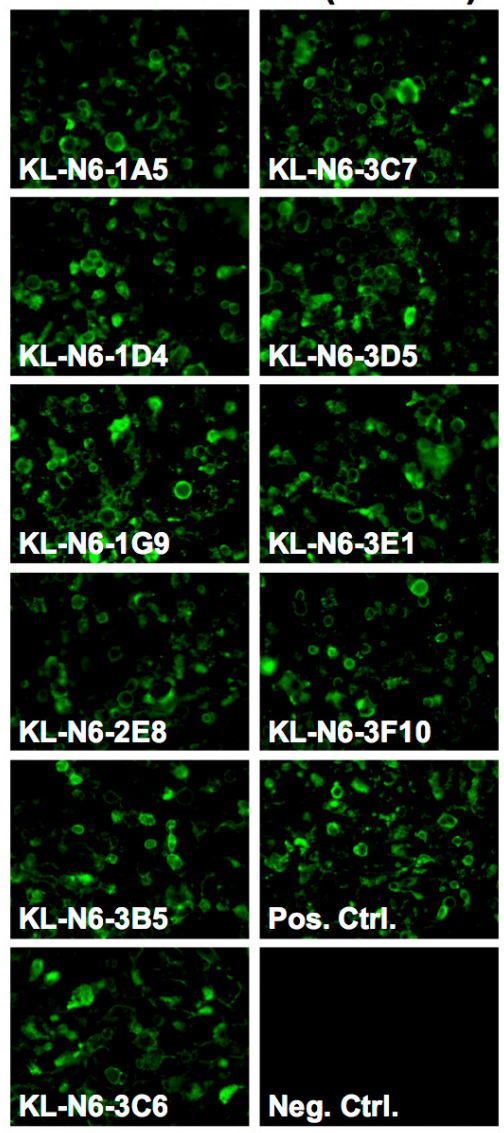

A/duck/Wisconsin/ 480/1979 (H12 6 )

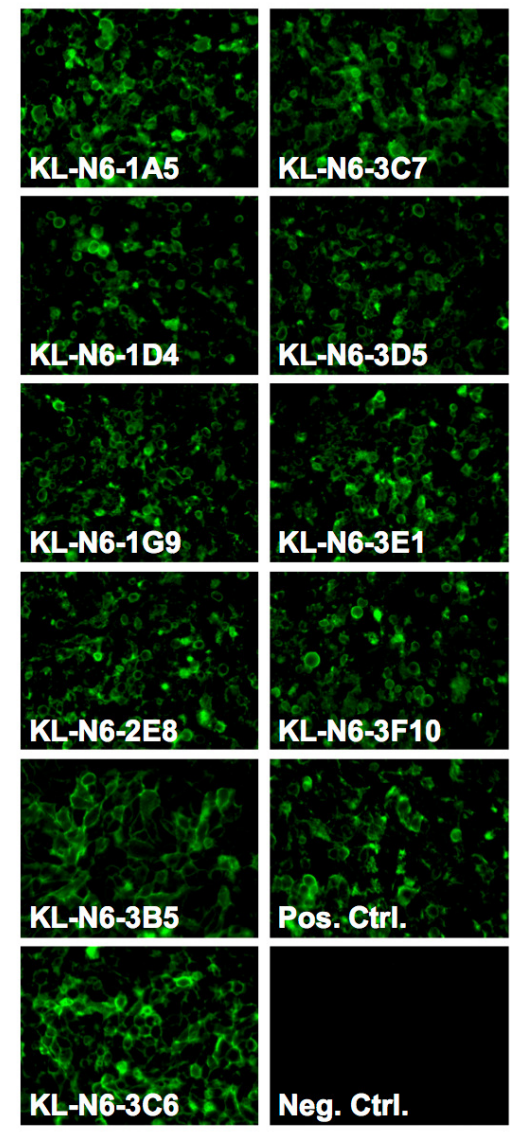

A/black-legged kittiwake/ Quebec/02838-1/2009 (H13 N6)

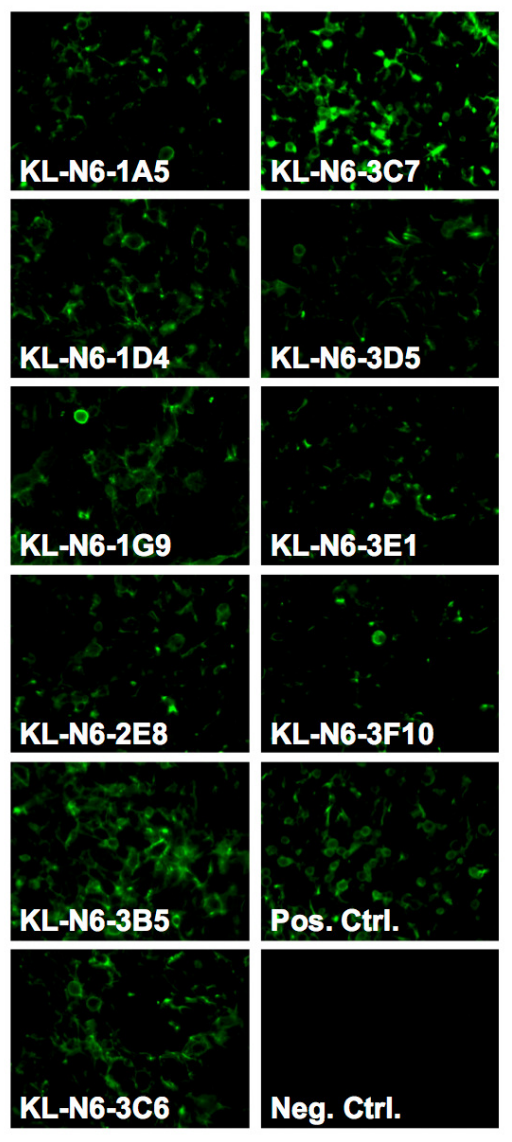


Neuraminidase inhibition assay A/duck/Czechoslovakia/1956 (H4N6)

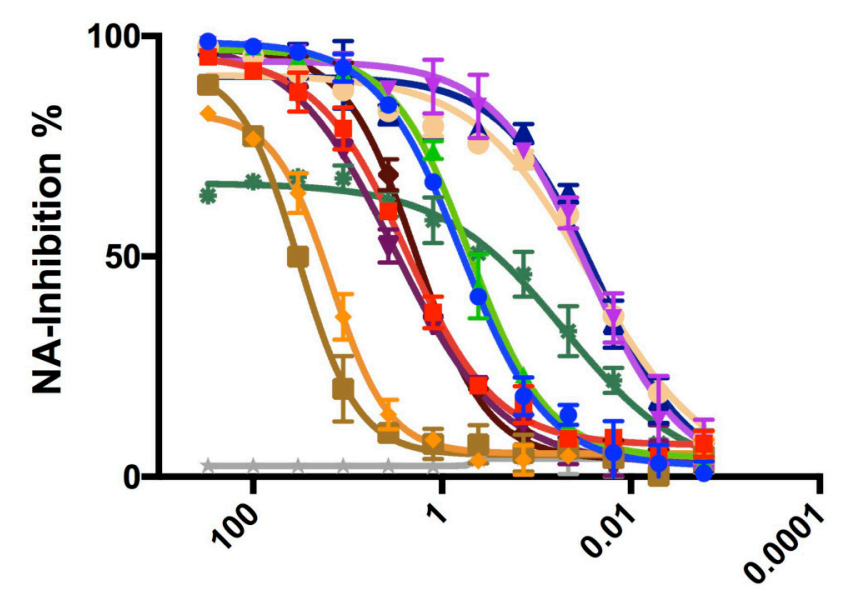

mAb concentration ( $\mu \mathrm{g} / \mathrm{ml}$ )

C

Neuraminidase inhibition assay A/Shenzhen/1/2016(H5N6)

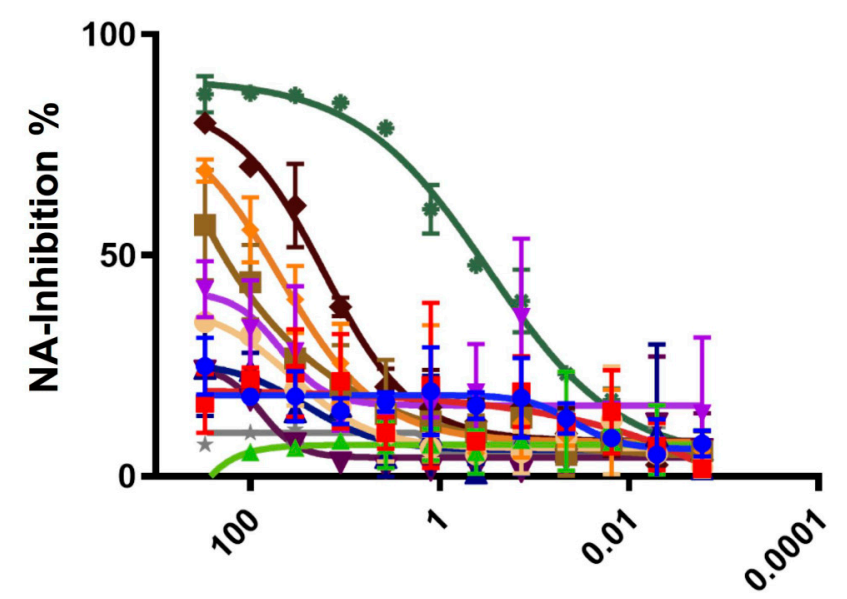

mAb concentration $(\mu \mathrm{g} / \mathrm{ml})$
Neuraminidase inhibition assay

A/swine/Missouri/A01727926/2015(H4N6)

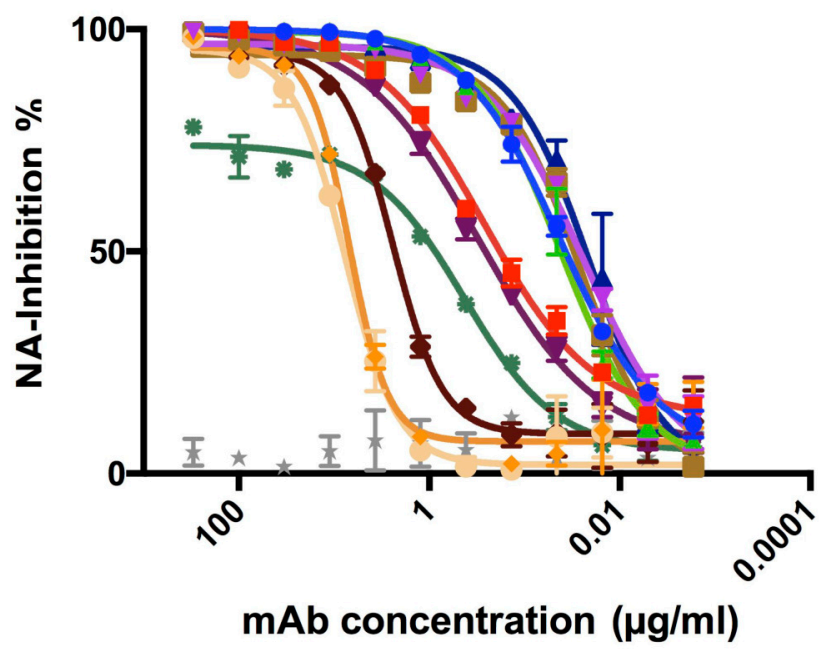

D
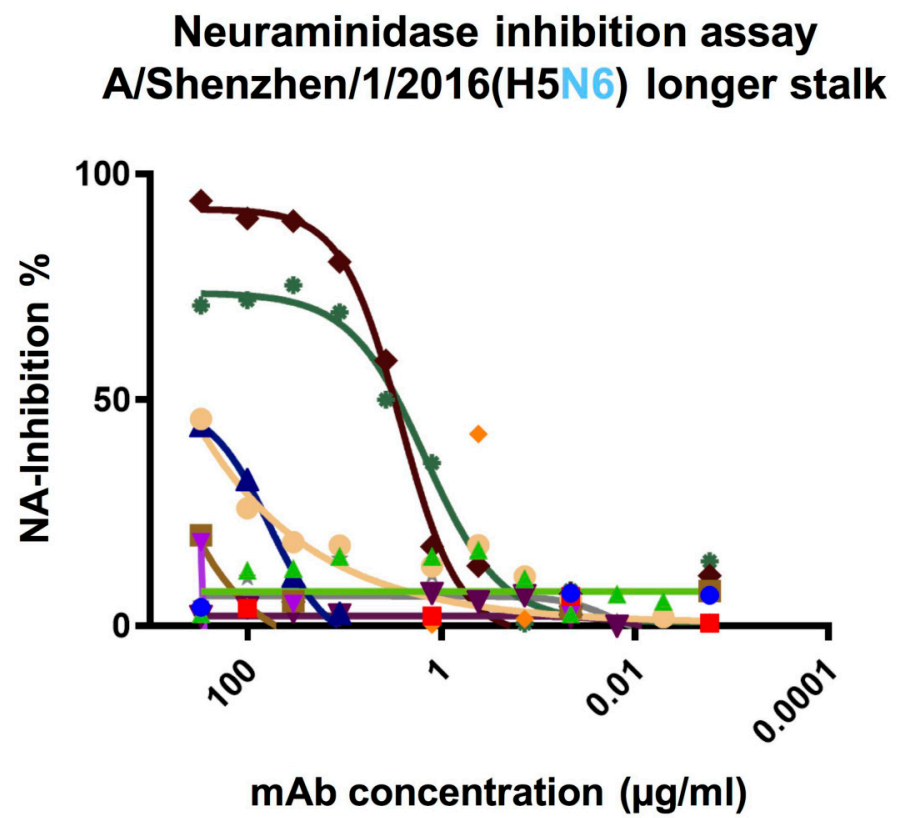

$\rightarrow \mathrm{KL}-\mathrm{N} 6-\mathrm{IA} 5$

$\Rightarrow \mathrm{KL}-\mathrm{N} 6-1 \mathrm{D} 4$

$\simeq \mathrm{KL}-\mathrm{N} 6-1 \mathrm{G} 9$

$\neq \mathrm{KL}-\mathrm{N} 6-2 \mathrm{E} 8$

$\sim \mathrm{KL}-\mathrm{N} 6-3 \mathrm{~B} 5$

$=\mathrm{KL}-\mathrm{N} 6-3 \mathrm{C} 6$

$=\mathrm{KL}-\mathrm{N} 6-3 \mathrm{C} 7$

$\pm \mathrm{KL}-\mathrm{N6} 6-3 \mathrm{D} 5$

$\rightarrow \mathrm{KL}-\mathrm{N} 6-3 \mathrm{E} 1$

$\rightarrow$ KL-N6-3F10

* Pos. Ctrl.

$\therefore$ Neg. Ctrl. 
PRNT assay

Plaque size reduction

A/duck/Czechoslovakia/1956 (H4N6)

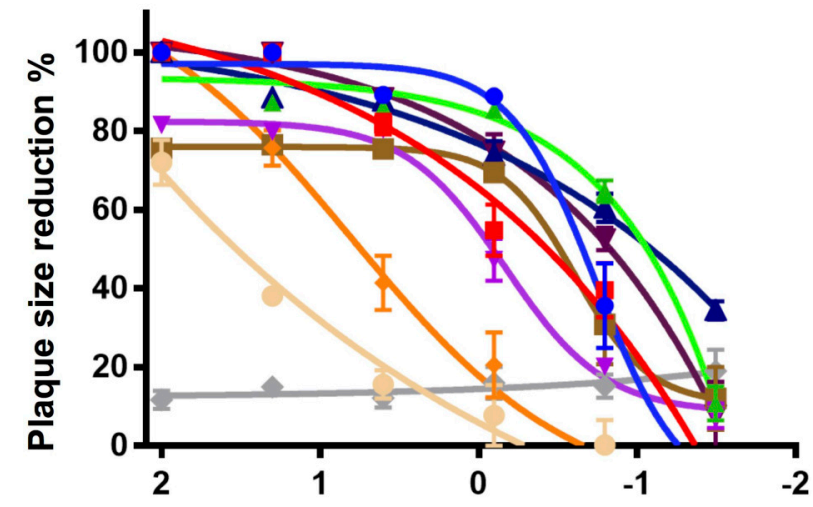

mAb concentration $(\mu \mathrm{g} / \mathrm{ml})$
0

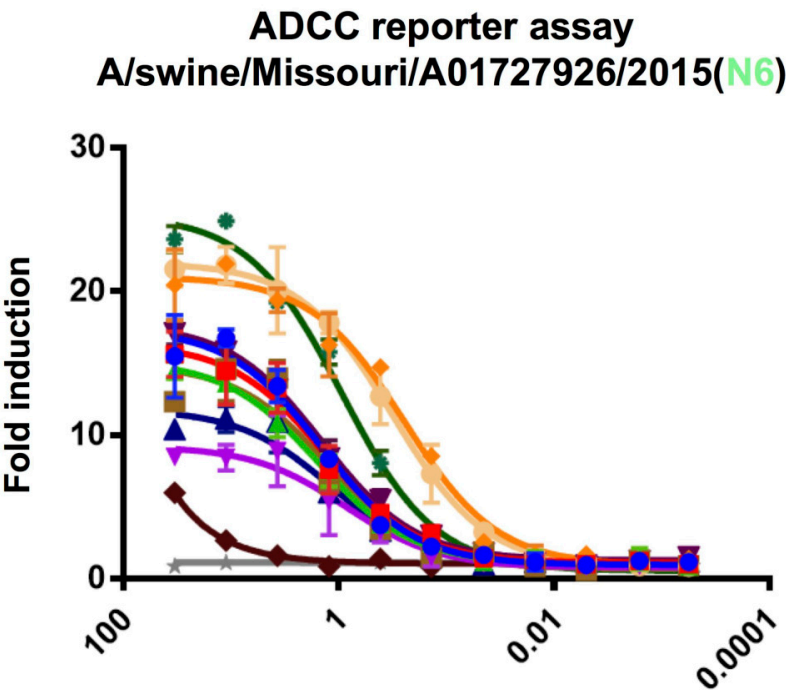

mAb concentration $(\mu \mathrm{g} / \mathrm{ml})$

ADCC reporter assay

A/Shenzhen/1/2016(N6)

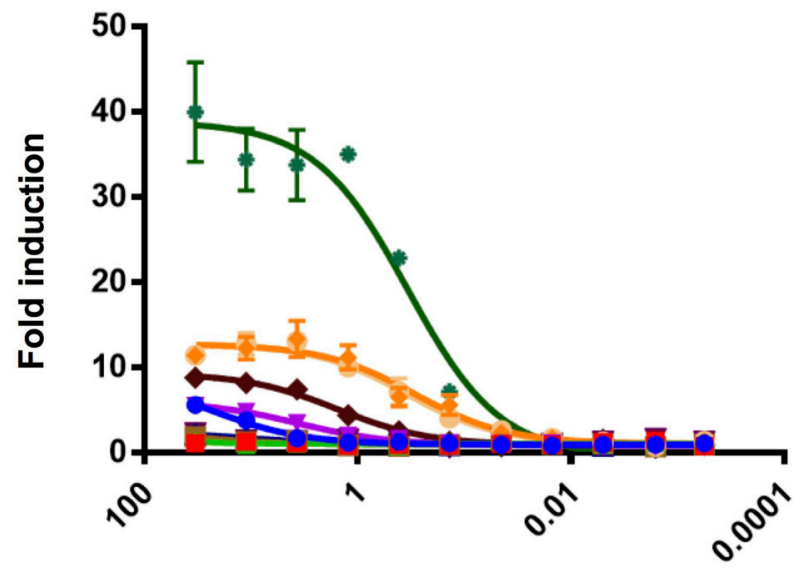

mAb concentration $(\mu \mathrm{g} / \mathrm{ml})$

E
PRNT assay

Plaque number reduction

A/duck/Czechoslovakia/1956 (H4N6)

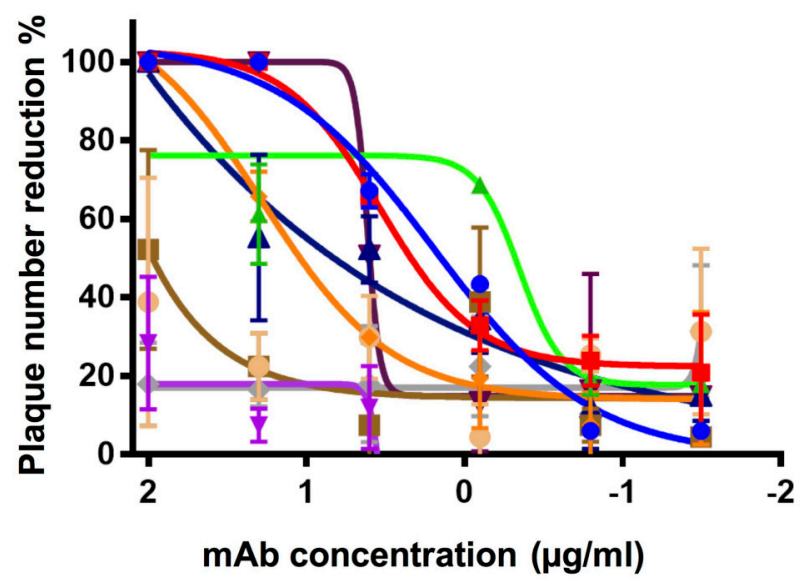

D

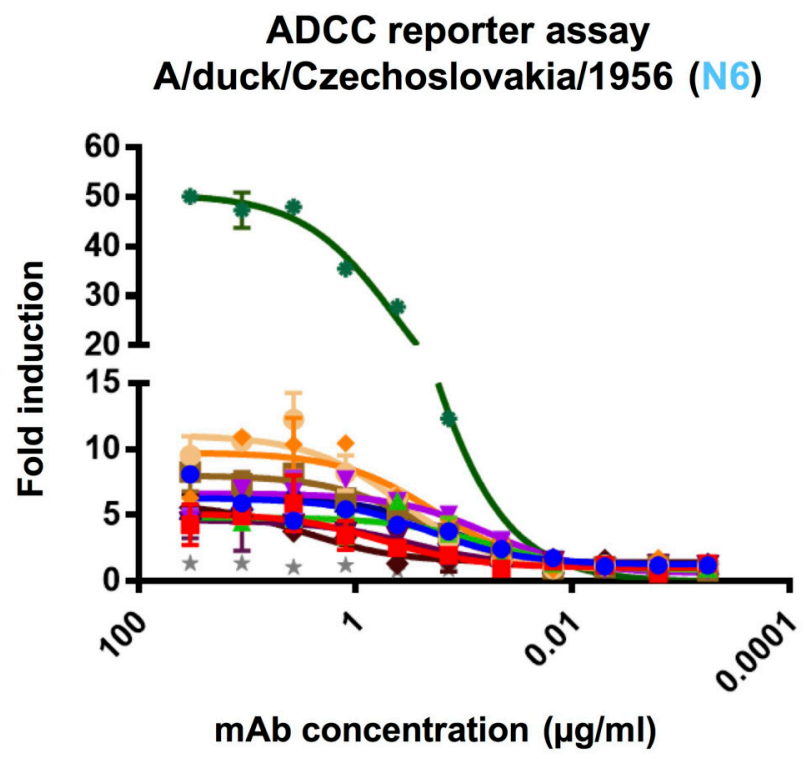

$\rightarrow$ KL-N6-IA5

$\rightarrow \mathrm{KL}-\mathrm{N6} 6-1 \mathrm{D} 4$

$\pm \mathrm{KL}-\mathrm{N} 6-1 \mathrm{G} 9$

$\rightarrow \mathrm{KL}-\mathrm{N} 6-2 \mathrm{E} 8$

$\leadsto$ KL-N6-3B5

KL-N6-3C6

- KL-N6-3C7

$\pm \mathrm{KL}-\mathrm{N6} 6-3 \mathrm{D} 5$

$\rightarrow \mathrm{KL}-\mathrm{N} 6-3 \mathrm{E} 1$

$\sim \mathrm{KL}-\mathrm{N6} 6 \mathrm{~F} 10$

* Pos. Ctrl.

$\leftarrow$ Neg. Ctrl. 
$\mathbf{A}$

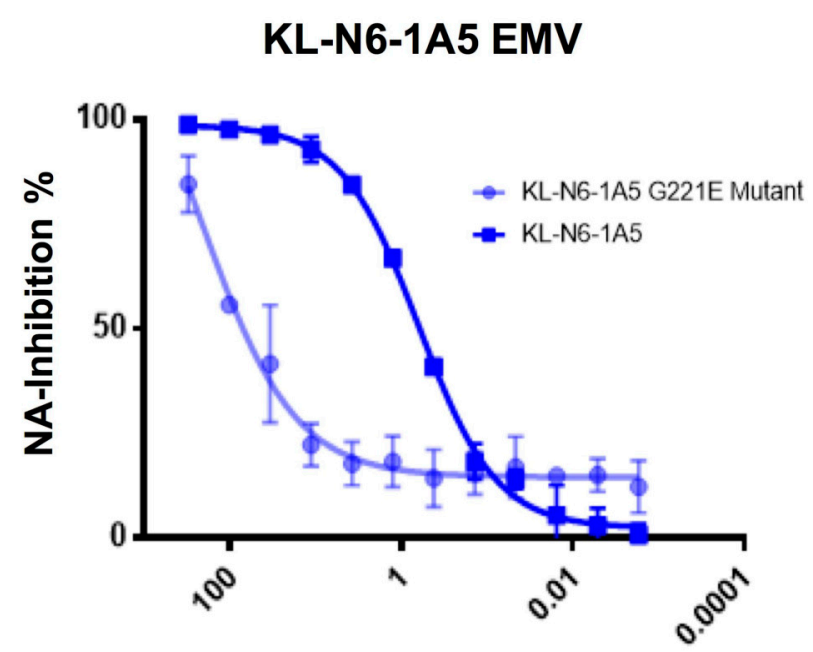

mAb concentration $(\mu \mathrm{g} / \mathrm{ml})$

D

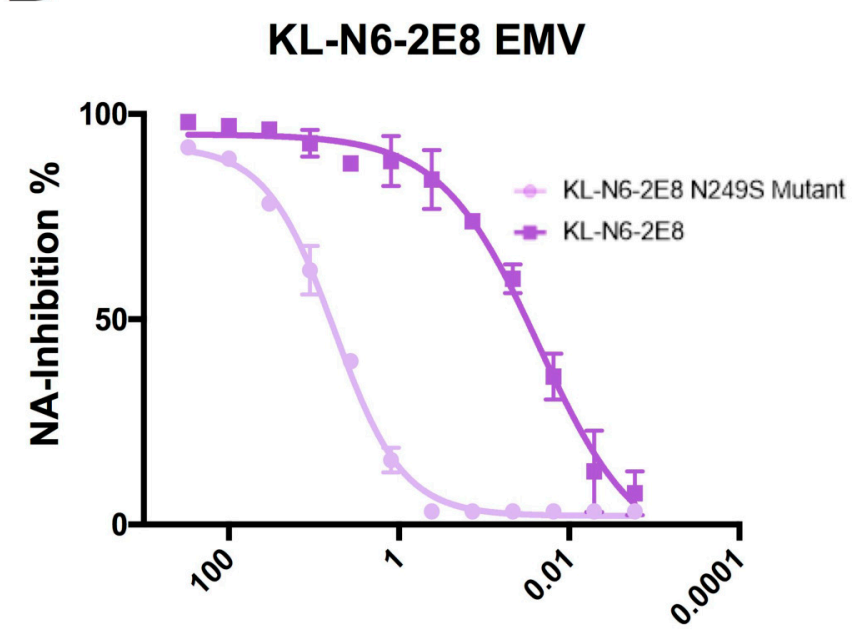

mAb concentration $(\mu \mathrm{g} / \mathrm{ml})$

\section{KL-N6-1D4 EMV}

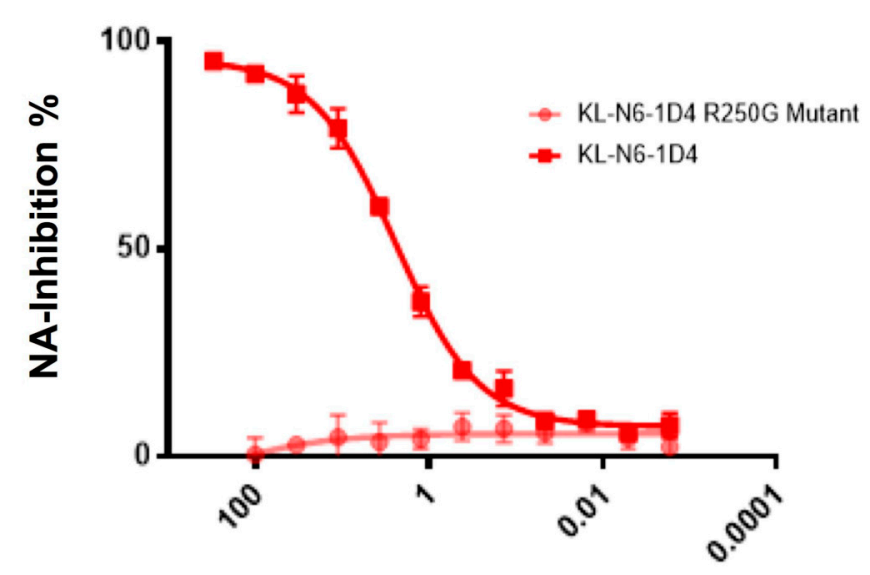

mAb concentration $(\mu \mathrm{g} / \mathrm{ml})$

E

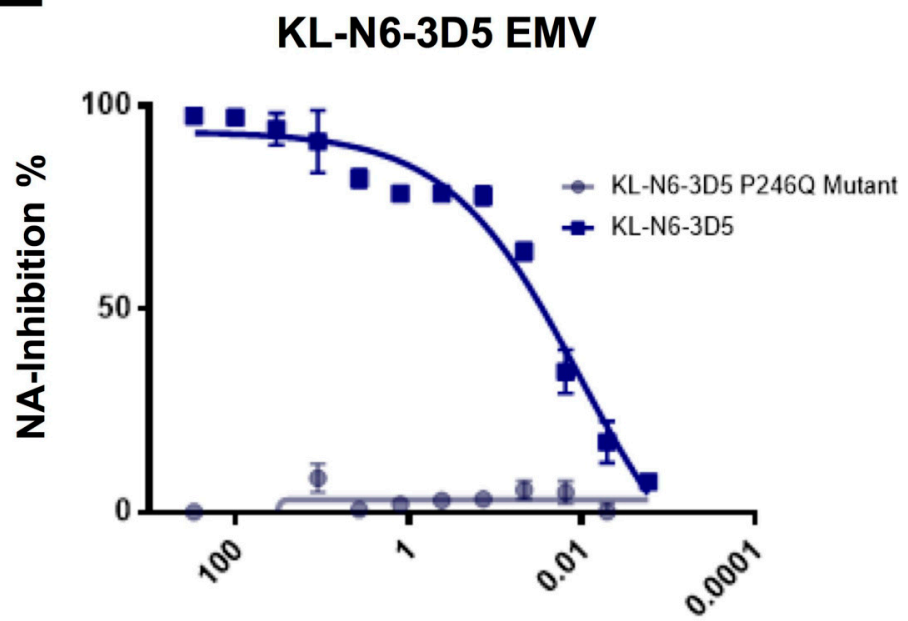

mAb concentration ( $\mu \mathrm{g} / \mathrm{ml})$
C

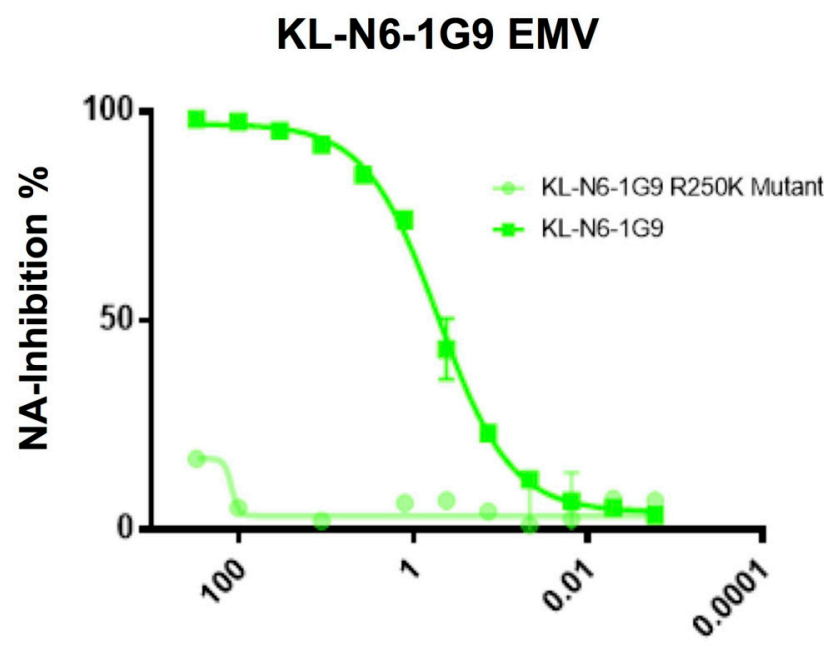

mAb concentration $(\mu \mathrm{g} / \mathrm{ml})$

$\mathbf{F}$

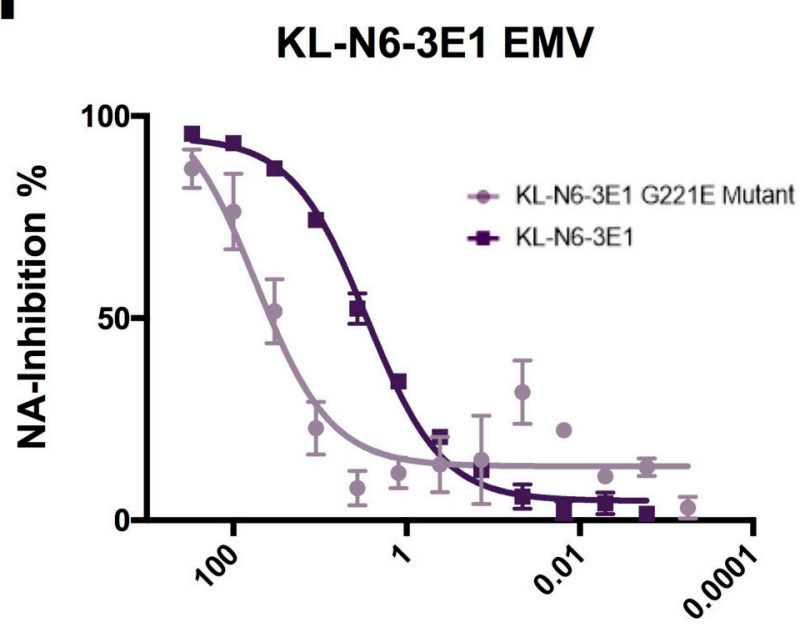

mAb concentration $(\mu \mathrm{g} / \mathrm{ml})$ 


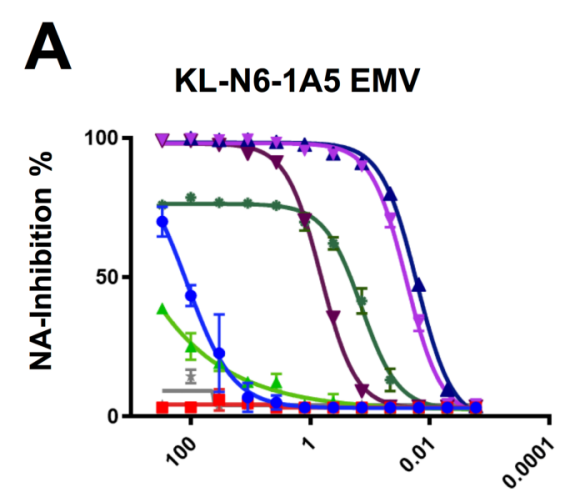

mAb concentration $(\mu \mathrm{g} / \mathrm{ml})$

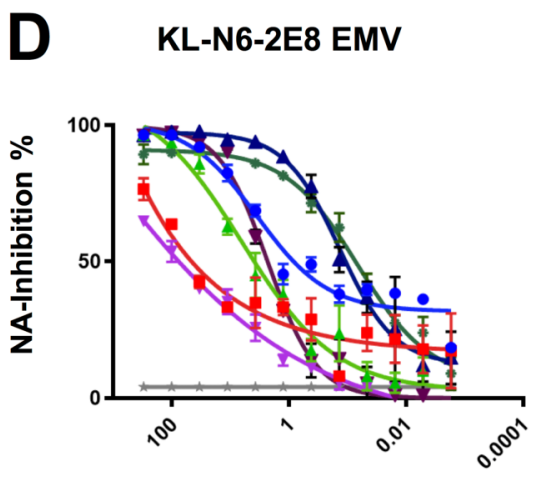

mAb concentration $(\mu \mathrm{g} / \mathrm{ml})$

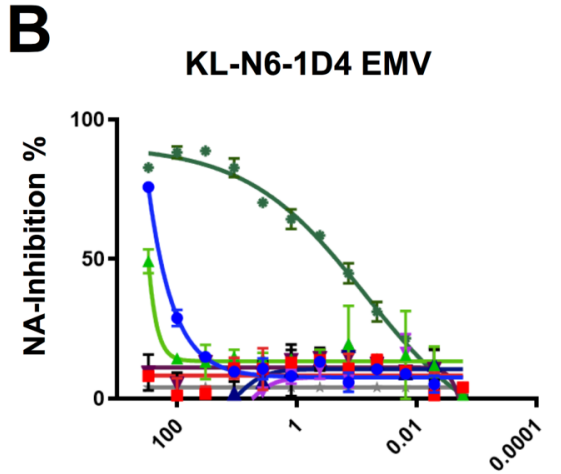

mAb concentration $(\mu \mathrm{g} / \mathrm{ml})$

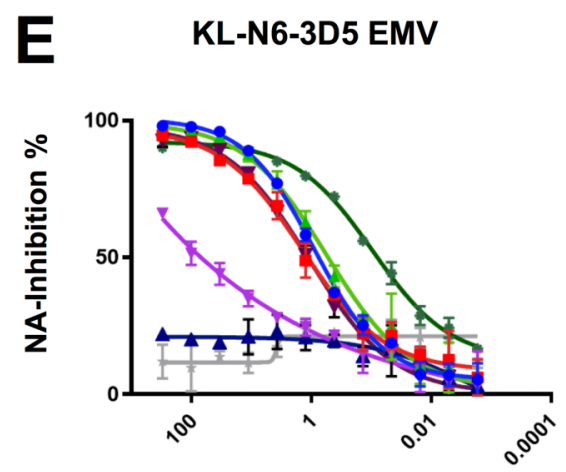

mAb concentration $(\mu \mathrm{g} / \mathrm{ml})$

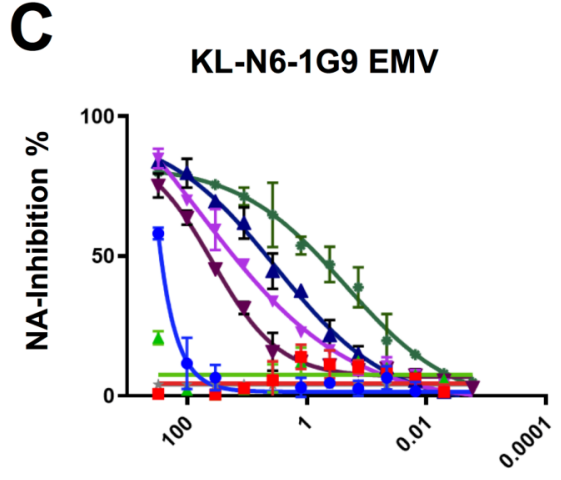

mAb concentration $(\mu \mathrm{g} / \mathrm{ml})$

E

KL-N6-3E1 EMV

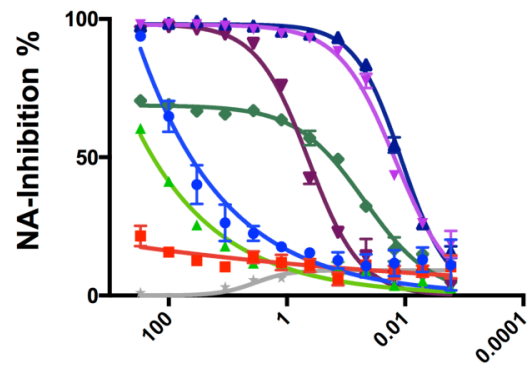

mAb concentration $(\mu \mathrm{g} / \mathrm{ml})$ $\rightarrow \mathrm{KL}-\mathrm{N} 6-\mathrm{IA} 5$

$+\mathrm{KL}-\mathrm{N6} 6-1 \mathrm{G} 9$

$\div \mathrm{KL}-\mathrm{N} 6-2 \mathrm{E} 8$

$\pm \mathrm{KL}-\mathrm{N} 6-3 \mathrm{D} 5$

$\rightarrow \mathrm{KL}-\mathrm{N} 6-3 \mathrm{E} 1$

- Pos. Ctrl.

- Neg. Ctrl. 
Weight loss

A/duck/Czechoslovakia/1956 (H4N6)

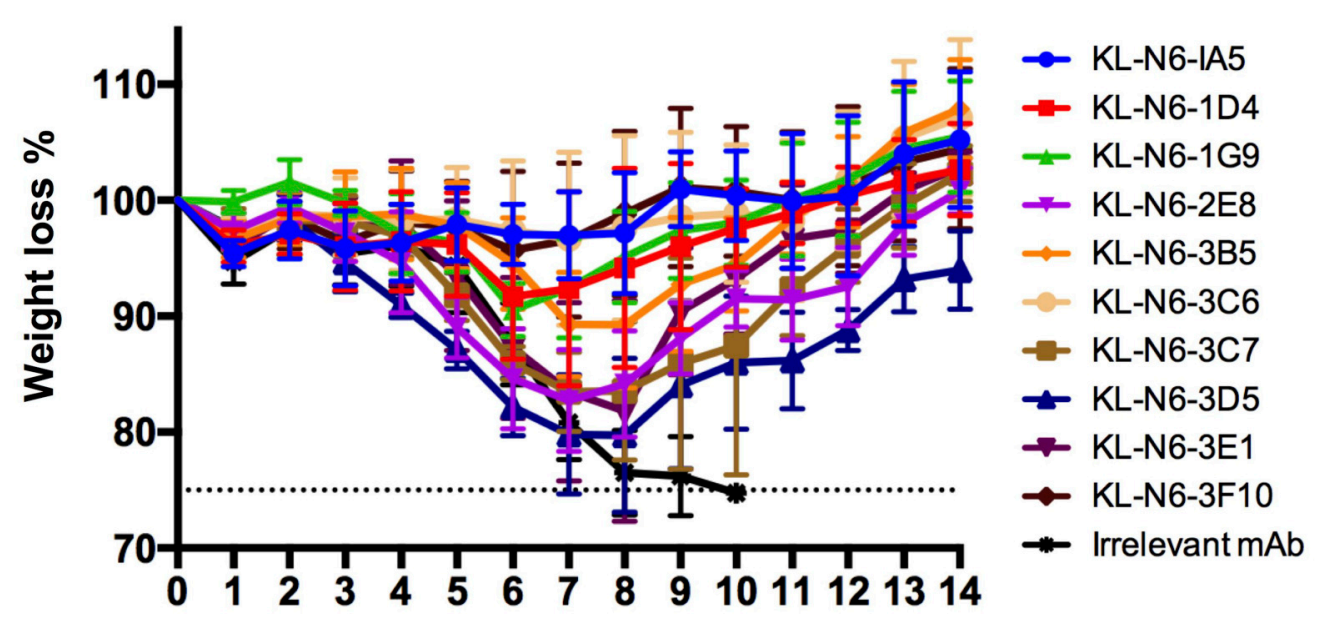

Days post challenge

C

Weight loss

A/Shenzhen/1/2016(H5N6)

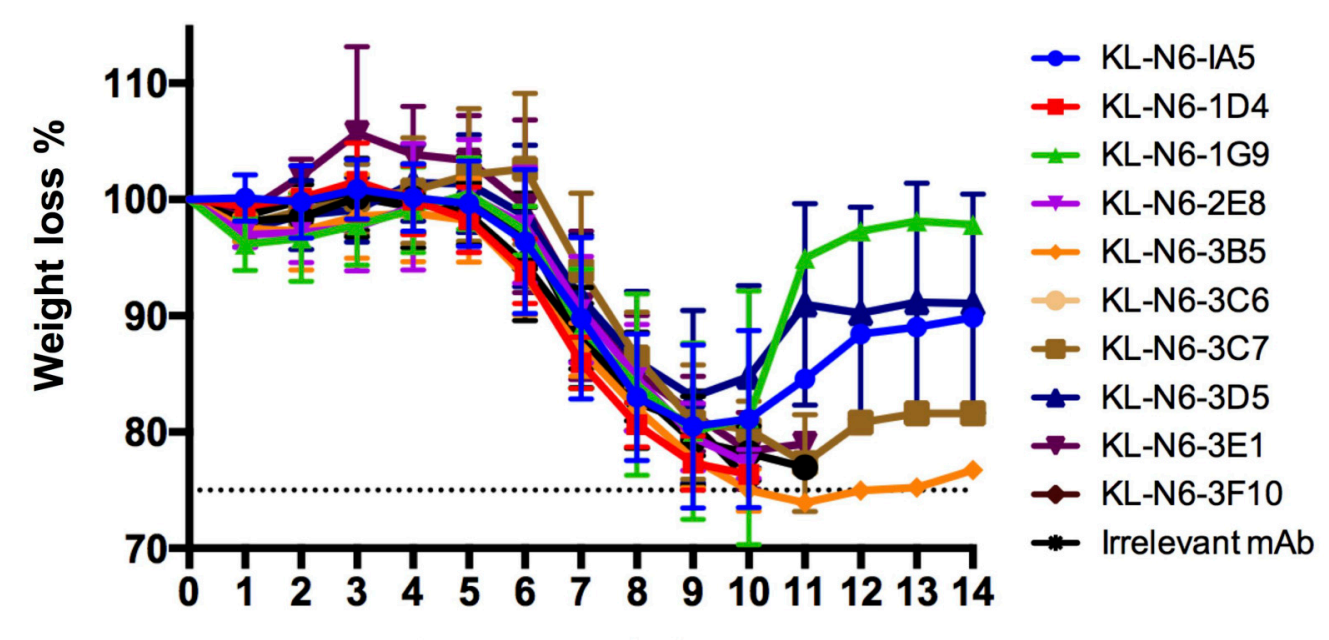

Days post challenge
Survival

A/duck/Czechoslovakia/1956 (H4N6)

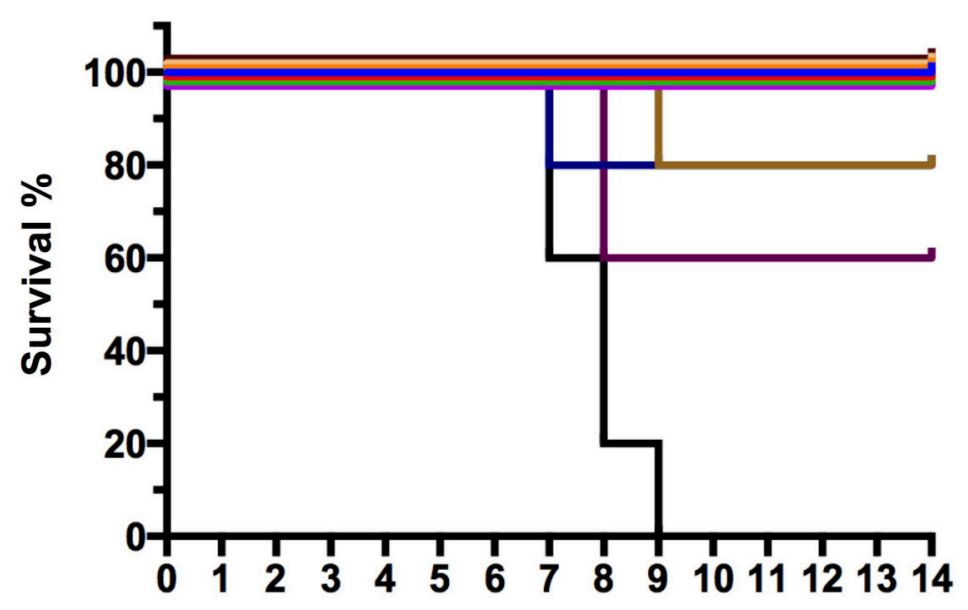

Days post challenge

D

\section{Survival}

A/Shenzhen/1/2016(H5N6)

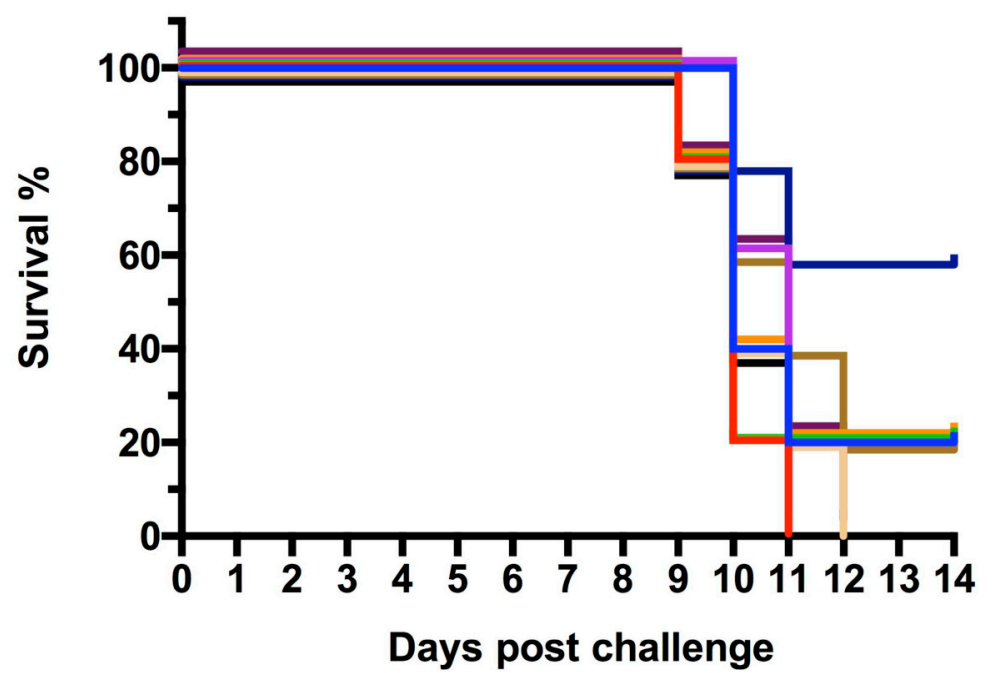

$\rightarrow$ KL-N6-IA5

- KL-N6-1D4

- KL-N6-1G9

- KL-N6-2E8

$\rightarrow$ KL-N6-3B5

$-\mathrm{KL}-\mathrm{N} 6-3 \mathrm{C} 6$

$-\mathrm{KL}-\mathrm{N} 6-3 \mathrm{C} 7$

- KL-N6-3D5

$\rightarrow$ KL-N6-3E1

$\rightarrow$ KL-N6-3F10

- Irrelevantmab

$\rightarrow$ KL-N6-IA5

$\rightarrow$ KL-N6-1D4

- KL-N6-1G9

$\rightarrow$ KL-N6-2E8

$\rightarrow$ KL-N6-3B5

- KL-N6-3C6

- KL-N6-3C7

- KL-N6-3D5

$\rightarrow \mathrm{KL}-\mathrm{N6} 6-3 \mathrm{E} 1$

$\rightarrow \mathrm{KL}-\mathrm{N6} 6-3 \mathrm{~F} 10$

$\rightarrow$ Irrelevant mAb 